\title{
Kapitel 15 \\ Die impliziten Erzählungen im „narrative approach“
}

\section{Vorbemerkung}

In Teil III dieser Arbeit wurde der Frage nach „Paulus als Erzähler“ zunächst durch eine umfassende Analyse expliziter Erzählungen nachgegangen. Ein solches Vorgehen wurde gegenüber Anfragen aus verschiedenen Richtungen abgesichert.

Die (1) in der Forschung weitverbreitete Skepsis gegenüber der Relevanz einer narratologischen Perspektive auf die Paulusbriefe wurde als größtenteils forschungsgeschichtlich bedingt und nicht ausreichend begründet kritisiert (Kapitel 1): Aus textlinguistischer Sicht stellte sich die Beschreibung des narrativen Anteils am Muster der Textsorte der Paulusbriefe vielmehr als wichtige Aufgabe dar. Die empirische Analyse der Texte (Kapitel 4-8) bestätigte die Berechtigung dieser Perspektive und zeigte die große Bedeutung auf, welche die Beachtung narrativer Vertextungen für das richtige Verständnis der Textfunktion der Briefe des Paulus hat (Kapitel 8, Abschnitt 4).

Die auch im Rahmen des (2) „narrative approach to Paul“ aus nicht überzeugenden Gründen (Kapitel 2) stiefmütterlich behandelten expliziten Erzählungen erfahren auf diese Weise eine Aufwertung. Ziel dieser Fokussierung auf narrative Vertextungen in den Paulusbriefen war die Überführung eines über weite Strecken prätheoretischen narrativen Ansatzes in einen theoriegeleiteten „narratological approach to Paul.“ Die in Teil II gebotenen Überlegungen stellen die Frage nach „Paulus als Erzähler“ auf eine methodologisch fundierte und empirisch zumindest in groben Zügen umrissene Basis, die so im „narrative approach“ bisher nicht auszumachen war.

Damit ist natürlich nicht gesagt, dass mit der Verschiebung vom narrativen Ansatz zur narratologischen Perspektive auch eine vollständige Substitution des Untersuchungsgegenstandes einhergehen müsste, also ein Interesse an expliziten statt an impliziten Erzählungen ermutigt werden soll. Vielmehr erwuchs gerade aus dem zusätzlichen Fokus auf den paulinischen Erzählstil als Anschlussfrage diejenige nach impliziten Erzählungen (Kapitel 8, Abschnitt 8).

Deswegen wurde in den Kapiteln von Teil III dieser Arbeit auf konstruktive Weise der Frage nachgegangen, welchen (a) narratologischen Stellenwert und (b) exegetischen Nutzen die von Hays und Wright ins Zentrum gerückte große Kategorie „impliziter“ Erzählungen haben könnte. 
Nachdem mentale Narrativisierung und daraus hervorgehende simulierte Protoerzählungen als ernstzunehmende Faktoren der Textproduktion identifiziert wurden (Kapitel 9) und zukünftige (Kapitel 10) und diserzählte (Kapitel 11) Ereignisse als relevante Erzählfragmente identifiziert worden waren, wurde anhand einiger Textbetrachtungen (Kapitel 12-14) dargelegt, dass implizite Erzählungen dieser Art tatsächlich einen großen heuristischen Wert für die Exegese versprechen.

Abschließend soll nun in Teil IV der Bogen zurück zu den konkreten Konzeptionen von Hays und Wright geschlagen werden. Vor dem Hintergrund der bisher besprochenen impliziten narrativen Strukturen lässt sich jetzt auch sinnvoll die Frage klären, wie die beiden Ansätze im Rahmen der hier entfalteten narratologischen Perspektive $z u$ verorten und $z u$ bewerten sind.

Dazu muss zunächst die Frage geklärt werden, was die Autoren im Einzelnen meinen, wenn sie von impliziten Narrativen sprechen, die sie so vehement von expliziten Erzählungen abgrenzen. Insbesondere muss zunächst auch erörtert werden, wie sich die Konzeptionen der beiden Exegeten zueinander verhalten, ob also hier ein gemeinsames Konzept vertreten wird, ob eher zwei divergierende Ansätze vorliegen oder ob hier letztlich mehrere zu unterscheidende Kategorien angesprochen werden, die aber teilweise überlappend bei beiden Autoren in Erscheinung treten. Im Anschluss an diese Analyse kann dann die Einordnung und Bewertung in den bisher ausgearbeiteten Rahmen einer narratologischen Perspektive auf die Paulusbriefe erfolgen.

\section{Richard B. Hays}

\subsection{Vorbemerkung}

Es wurde oben (Kapitel 2, Abschnitt 2.3) bereits auf Hays’ Definition von ,story im Gegenüber zu den Kategorien ,myth` und ,narrative' eingegangen. Letztere zeichnen sich durch ihre konzeptuelle Nähe zum von Hays primär in den Fokus des Interesses gerückten Gegenstand, seine „narrative substructures,“ aus. Das genauere Verständnis dieses Untersuchungsgegenstandes erhellt sich aber aus Hays’ Diskussion des Verhältnisses von ,story‘ zu auf den ersten Blick disparaten Konzeptionen, wie etwa dem der Argumentation. Ehe sich die folgende Betrachtung auf diese Verhältnisbestimmungen konzentrieren kann, wird es zunächst aber lohnend sein, eine Verortung der Arbeit The Faith of Jesus Christ als Ganzer im Forschungskontext vorzunehmen. 


\subsection{Verortung der These}

\subsubsection{Die ursprüngliche Verortung}

\subsubsection{Gegenspieler}

Kapitel $1^{1}$ von The Faith of Jesus Christ beschäftigt sich mit der Suche nach „konstanten Elementen“ im paulinischen Evangelium. ${ }^{2}$ Während es in Bezug auf die Schriften anderer Denker möglich sei, „to ,follow' the reasoning that undergirds the text, “ sei dies im Hinblick auf einen Paulusbrief aufgrund seines „,occasional" character" sehr viel schwieriger. ${ }^{3}$

Mit Bezug auf J. C. Beker ${ }^{4}$ spricht Hays davon, dass in den Briefen des Apostels der „Kern“ des Evangeliums in eine dynamische Interaktion mit spezifischen Umständen gebracht werde. ${ }^{5}$ Es sei natürlich Gegenstand der historisch-kritischen Exegese, diese individuellen Verhältnisse zu rekonstruieren, in welche hinein Paulus spreche. ${ }^{6}$ Genauso gehöre jedoch zum Aufgabenbereich die Klärung der Frage, ,what Paul brought to these encounters. “7 Und damit meint Hays gerade nicht nur den spezifischen kommunikativen Beitrag, welcher sich aus dem Zusammenspiel von konkreten Gegebenheiten und den konstanten Elementen des paulinischen Evangeliums ergibt, sondern diesen letztgenannten Aspekt selbst, das heißt ,the framework out of which Paul reacted to the pastoral problems that appear in his letters."

Die Frage nach diesen konstanten Elementen sei in der Auslegungsgeschichte, so Hays, nahezu ausschließlich durch Verweis auf paulinische „Konzepte“ (engl.: „ideas“) gegeben worden, also auf den dogmatisch-lehrmäßigen (engl. „doctrinal“) Inhalt seines Denkens. ${ }^{9}$ Die ältere protestantische Orthodoxie habe in ihrer Exegese Paulus als systematischen Theologen behandelt, dessen Lehre verstanden werden könne „as a compendium of theological propositions,“ also von „Lehrbegriffe[n].“10 Das von Hays auf das späte 19. Jahrhundert datierte wachsende Bewusstsein dafür, dass der Apostel eben kein systematischer Theologe gewesen sei und dass seine Schriften, als theologische Traktate gelesen,

1 Hays, Faith, 1-31.

2 Die Überschrift lautet: „The Search for the Constant Elements of Paul's Gospel“ (Hays, Faith, 1).

3 Hays, Faith, 1.

4 Beker, „Contingency and Coherence.“

5 Hays, Faith, 1.

6 Hays, Faith, 2.

7 Hays, Faith, 2.

8 Hays, Faith, 2.

9 Hays, Faith, 2.

10 Hays, Faith, 2. 
einen äußerst unbefriedigenden Eindruck machen würden, hätte dennoch nichts daran geändert, dass sich die Paulusforschung weiterhin als „quest for conceptual formulations" verstanden hätte. ${ }^{11}$

Ein solches Vorgehen führt nach Hays jedoch in ein Dilemma: Entweder bildet ein zentraler theologischer Leitgedanke den Kern der paulinischen Theologie, während alle anderen in den Briefen zum Ausdruck kommenden Ansichten entweder als von diesem abgeleitet oder als nebensächlich gelten müssten. ${ }^{12} \mathrm{Er}$ verweist hier etwa auf E. P. Sanders' Paul and Palestinian Judaism, welches Albert Schweitzers Anliegen fortführte, die Lehre von der Rechtfertigung zum Nebenkrater der paulinischen Theologie und Partizipation zu dessen Zentrum zu erklären. ${ }^{13}$ Ein solcher Ansatz habe das Problem, das große Teile der paulinischen Briefliteratur (wie etwa in diesem Fall Röm 1-5) als „peripher“ für die Theologie des Paulus eingestuft würden. ${ }^{14}$ Alternativ zu diesem Ansatz bestehe die Möglichkeit, ein bestimmtes theologisches Konzept so sehr aufzublasen, dass es alle anderen „conceptual schemata in Paul's letters“ unter seiner eigenen Überschrift subsumiere. Diese Strategie sieht Hays - im Hinblick auf die Rechtfertigungslehre - bei Luther begründet und durch Käsemann (bis zur Belastungsgrenze) auf die Spitze getrieben. ${ }^{15}$

Welche Möglichkeiten bleiben nach Hays jenseits dieser Fokussierung auf „theological ideas“? Hays nennt zwei fundamentale Zugänge: Zum einen den Versuch, die Theologie des Paulus zu verstehen als „,an expression of his personal subjective religious experience,“ zum anderen die Hinzunahme von „existentialist categories. “16 Kronzeuge für den ersten Ansatz ist Adolf Deissmanns Kritik des Paulus als eines dogmatischen Theologens und sein Alternativvorschlag der Betonung von Paulus’ „personal experience of mystical union with Christ.“17 Hinzu gesellt Hays außerdem Wilhelm Bousset mit seiner religionsgeschichtlichen Betonung des hellenistischen Christentums als Kontext der paulinischen Begegnung mit dem Kyrios Christos. ${ }^{18}$ Hays sieht in diesen Ansätzen ein

11 Hays, Faith, 2.

12 Hays, Faith, 3.

13 Hays, Faith, 34 mit Verweis auf Schweitzer, Mysticism. Siehe Hays, „Introduction,“ xxv-xxvi für eine spätere Stellungnahme zu Sanders, in welcher er einräumt, dass er zur Zeit der Abfassung seiner Dissertation gerade erst dabei war „to grapple with the consequences of this transformation [of Sanders's picture of Palestinian Judaism] for the construal of Paul's theology.“

14 Hays, Faith, 3.

15 Hays, Faith, 3: „Käsemann's highly elastic interpretation of ,righteousness“ stretches the concept nearly to its breaking point.“

16 Hays, Faith, 3.

17 Hays, Faith, 3 mit Verweis auf Deissmann, Paul.

18 Hays, Faith, 4. 
Korrektiv gegenüber vorhergehenden Interpretationsmustern, in welchen Paulus behandelt wurde, als sei er ein „professor of theology“ gewesen. Der entscheidende Schwachpunkt dieses Paradigmas sei jedoch, dass der valide Verweis auf die intensive persönliche religiöse Erfahrung des Apostels die folgende zentrale Frage nicht beantworte: ${ }^{19}$

[W]hat were the structures of thought within which this experience took place and by means of which he tried to communicate it to others?

Der Verweis auf nonverbale mystische Erfahrungen sei ungenügend, denn die Erfahrung erhalte ihre Form in, mit und durch die Sprache, mit welcher sie „apprehended and interpreted“ werde. ${ }^{20}$ Auch die von Joachim Jeremias vertretene Interpretation des Damaskus-Erlebnis als „Schlüssel zur paulinischen Theologie“ scheitere analog daran, dass man hierin zwar eine kausale Erklärung für den Umschwung im Lebensweg des Paulus finden könne, aber dadurch kaum Form und Inhalt des paulinischen Denkens verständlich würden. ${ }^{21}$

Die existentialistische Interpretation Rudolf Bultmanns sei schwieriger zu bewerten und lasse sich nicht so leicht klassifizieren: „This ,self-understanding, as exposited by Bultmann, is experiential without being mystical and conceptual without being doctrinal.“22 Obwohl Bultmann dezidiert kritisch gegenüber der Reduktion des Glaubens auf dogmatische Propositionen sei, attestiert Hays ihm doch, dass er das paulinische Denken formal, wenn nicht auch inhaltlich, behandle ,as a structure of theological concepts that may be elucidated through systematic exposition." 23 Darüber hinaus würden große Teile der paulinischen Sprache als „mythologisch“ und damit gegenstandslos für die Sache - d.h. „the theological substance of Paul's thought“ - deklariert. ${ }^{24}$ In dieser Hinsicht bezweifelt Hays, dass es tatsächlich möglich sei, das paulinische Denken einfach in nicht-mythologische Kategorien zu ,übersetzen. “25 Er wirft vor diesem Hintergrund daher die Frage auf, ob es nicht auch einen gangbaren Weg geben könnte, auf welchem die konstanten Elemente des paulinischen Evangeliums in einer Darstellung wiedergegeben würden, die „more faithful to the forms in which Paul actually thought" wäre. ${ }^{26}$

19 Hays, Faith, 4.

20 Hays, Faith, 4.

21 Hays, Faith, 4.

22 Hays, Faith, 5.

23 Hays, Faith, 5.

24 Hays, Faith, 5.

25 Hays, Faith, 5.

26 Hays, Faith, 6. 
Damit leitet Hays seinen eigenen Ansatz ein. Die Form des paulinischen Denkens sei sicherlich nicht einfach zufällig. Vielmehr, so schlägt er vor, müsse jeder Versuch, das Wesen und die Natur der theologischen Sprache des Paulus zu bestimmen, mit der „centrality of narrative elements in his thought“ rechnen. ${ }^{27}$ Was der paulinischen Reflexion über variable Umstände in den Gemeinden Form gebe, sei eine „sacred story,“28 eine „narrative structure.“29

Damit meint Hays nun nicht, dass Paulus diese Geschichte in seinen Briefen schlicht nacherzähle. Vielmehr setze Paulus voraus, dass seine Leser diese „gospel story“ kannten, sodass er sich auf dieser Grundlage beständig darum bemüht habe, deren Implikationen für die jeweilige Situation der Gemeinde aufzuzeigen. Man könne die multifaktorisch entstandenen Briefe daher nicht einfach hernehmen und diese Geschichte wie einen mathematischen Koeffizienten herauskalkulieren. Jedoch sei es möglich, Anspielungen (,allusions“) zu Paulus' Geschichte von Jesus Christus zu identifizieren und so herauszufinden, (1) welche narrative Form sie habe und (2) auf welche Weise sie die Logik der paulinischen Argumentation bestimme.

\subsubsection{Vorläufer}

Hays' Ansatz kann gegenüber den von ihm skizzierten Alternativen durchaus als Neuansatz gelten, auch wenn er selbst natürlich Vorläufer benennt. ${ }^{30}$ Zum einen verweist er auf Forscher, die bereits explizit auf narrative Elemente in den Paulusbriefen aufmerksam gemacht hatten, jedoch den Aspekt nicht weiter ausführten. ${ }^{31}$ Zum anderen bespricht er in Kapitel 2 mit Cullmann, Dodd und Via (und im Ansatz Käsemann) auch Autoren, welche - im Gegensatz zu Bousset, Schweitzer und Bultmann - narrative Elemente nicht nur wahrgenommen, sondern diese auch für nicht einfach durch andere Konzepte ersetzbar angesehen hatten. ${ }^{32}$ Während sie, so Hays, aber Aspekte betont hätten, welche auch für sein Anliegen von Bedeutung seien, habe doch keiner von ihnen eine Interpretation der paulinischen Theologie „,as being rooted in story“ unternommen. ${ }^{33}$

27 Hays, Faith, 6.

28 Hays, Faith, 6 übernimmt diesen Ausdruck von Crites, „Narrative Quality,“ 295.

29 Hays, Faith, 6.

30 Zur Verortung der Arbeit Hays im Rahmen der narratologischen Forschungsgeschichte siehe oben, Kapitel 3, Abschnitt 6.2.

31 Diese sind Wilder, Theopoetic, Crites, „Angels,“ Sanders, „Torah“ und Beardslee, „Narrative Form.“ Vgl. Hays, Faith, 9-14.

32 Cullmann, History, Dodd, Apostolic Preaching und Via, Kerygma.

33 Hays, Faith, 9. 
Insgesamt bleibt im Hinblick auf alle angeführten Vorläufer der Eindruck größerer Distanz als Nähe zurück. So räumt Hays zwar ein, dass Cullmanns Konzeption der „Heilsgeschichte“ generell gesprochen geistesverwandt („congenial“) mit seiner These einer narrativen Substruktur sei. Denn immerhin biete diese einen Rahmen an Ereignissen, innerhalb dessen sich Paulus und seine Gemeinde orientierten. ${ }^{34}$ Jedoch ist für Hays das Paradigma von Cullmann viel $\mathrm{zu}$ sehr gesamtbiblisch orientiert, als dass es sich eignen würde, um spezifische paulinische Gedankengänge zu erhellen. ${ }^{35}$ Damit verbunden sieht Hays das Problem, dass „narrative“ Bezüge bei Paulus zu sehr in Kontinuität mit diesem großen Rahmen gelesen würden, also als simple „Entwicklungen“ („developments“) und dass darin der spezifisch paulinische Fokus, der auch Spannungen enthalte, verloren ginge. ${ }^{36}$

Bei Käsemann ist der von Hays erkannte Beitrag ein noch indirekterer: Durch die Verlagerung des Diskurses um die Rechtfertigung in die Apokalyptik werde bei ihm das theologische Denken des Paulus auf eine gewisse „narrative foundation“ gestellt. ${ }^{37}$ Damit meint Hays offensichtlich das grundsätzlich narrative Gepräge eschatologischer Rede. ${ }^{38}$ Auf formale Weise sei Käsemanns Ansatz daher analog zu seiner eigenen These: Käsemanns Interpretation setze ein „apokalyptisches Drama“ voraus, das im Bereich der nicht explizierten Voraussetzungen verbleibe, die das paulinische Denken vereinigten. ${ }^{39}$ Diese Tendenz sei zurückzuführen auf die Reaktion Käsemanns gegenüber seinem Lehrer Bultmann. Andererseits müsse jedoch festgehalten werden, dass Käsemann - aufgrund der ebenfalls wichtigen Frontstellung gegenüber der heilsgeschichtlichen Schule - gleichfalls kein Interesse daran gehabt hätte, diese neu betonten Aspekte, welche im Grunde gut verträglich mit einer narrativen Perspektive gewesen wären, weiter zu verfolgen. ${ }^{40}$

Mit Dodd hat Hays auf den ersten Blick vor allem die Kategorie der „Substruktur“ gemeinsam. ${ }^{41}$ Deren besondere Bedeutung bei Dodd macht jedoch auch zugleich den Unterschied zwischen den Entwürfen deutlich. Denn Dodd geht

34 Hays, Faith, 55.

35 Hays, Faith, 55.

36 Hays, Faith, 56. Für eine kurze Zusammenfassung seiner Abgrenzung von Cullmann, siehe Hays, Faith, 57-58.

37 Hays, Faith, 59.

38 Hays, Faith, 59: „Although Käsemann is considerably more cautious than Schweitzer in describing the specific content of Paul's eschatological scenario ..." Was hieran wichtig ist, ist nicht so sehr, was verneint wird, sondern was vorausgesetzt wird.

39 Hays, Faith, 60.

40 Hays, Faith, 60.

41 Dodd, Scriptures, 12-13. 
vom Kerygma als Größe hinter den Briefen aus: „They expound and defend the implications of the Gospel rather than proclaim it." 42 Zwischen das Kerygma und die theologische Explikation tritt bei Dodd nun die „Substruktur,“ welche aus alttestamentlichen Schriftstellen besteht, die auf das Evangelium bezogen sind..$^{43}$ Bemerkenswert ist, dass auch Dodd unwillkürlich narrative Kategorien („plot,“ „hero“ etc.) verwendet, wenn er diese Substruktur analysiert. Der Unterschied zu Hays' Entwurf besteht aber nun darin, dass für Dodd diese Substruktur gewissermaßen sinngebend ist für die Einzelaspekte, die er für die paulinische Predigt rekonstruiert. ${ }^{44}$ Wichtig ist nun einerseits, dass Dodd im Hinblick auf diese paulinischen Einzelaspekte selbst nicht explizit von einer Geschichte spricht, sondern von „ideas,“ „beliefs“ und „facts.““5 Selbst wenn man das Gepräge des Kerygmas nun im Sinne von Hays narrativer auffassen würde, wären die beiden Ansätze aber immer noch nicht deckungsgleich. Denn als weiterer, das Material der Substruktur betreffender Unterschied fällt auf, dass bei Hays die Christus-Geschichte die fundamentalere ist und die Auswahl und Interpretation der alttestamentlichen Texte bestimmt - und nicht umgekehrt. ${ }^{46}$ Letztendlich ist auch schlicht der Fokus ein anderer: Dodd sucht nach einer gesamt-neutestamentlich verbindenden Größe, Hays hat das spezifischere Anliegen, konkrete paulinische Texte zu erhellen. ${ }^{47}$

Abschließend bespricht Hays die Arbeit von Dan O. Via Jr., der meint, er könne eine „comic structure“ in den Paulusbriefen ausmachen..$^{48}$ Dabei geht es nicht darum, dass Paulus tatsächlich in der Produktion seiner Schriften abhängig von der griechischen Komödie gewesen sei. Vielmehr meint Via, es gebe gemeinsame zugrundeliegende Muster um Tod und Auferstehung, welche tiefer im menschlichen Bewusstsein verankert seien. ${ }^{49}$ Das innovative Element in Vias Ansatz ist, dass er auch Texte, die keine klar erkennbare narrative Struktur aufweisen, aufgrund bestimmter Konstellationen an Eigenschaften in eigentlich narrative Kategorien einordnen kann: ${ }^{50}$ „In 1 Cor 1:18ff. the narrative form is comic, ending on the note of life and justification, while in Rom 9:30ff. the narrative form is tragic, the last word being Israel's disobedience. "51

42 Dodd, Apostolic Preaching, 9.

43 Dodd, Scriptures, 12-13.

44 Hays, Faith, 61 mit Verweis auf Dodd, Apostolic Preaching, 17.

45 Vgl. Hays, Faith, 61-62.

46 Hays, Faith, 63.

47 Hays, Faith, 64.

48 Vgl. Via, Kerygma, 15.

49 Via, Kerygma, 49.

50 Vgl. Hays, Faith, 66.

51 Via, Kerygma, 50. 
Hays kann diesem Ansatz durchaus etwas abgewinnen: Zum einen sieht er in Vias Rede von der spezifischen Geschichte Jesu als ein „model outside himself“52 Potenzial für die Verbindung von Theologie und Ethik, ${ }^{53} \mathrm{zum}$ anderen begrüßt er natürlich dessen grundsätzliches Anliegen einer literarischen Analyse des „story-pattern“ der Paulusbriefe, welches er in der gängigen Exegese ausgeklammert sieht. ${ }^{54}$

Man ist jedoch gut darin beraten, auch Hays' deutliche Kritik wahrzunehmen, welche in durchaus brillanter Schärfe herausarbeitet, worin Gefahren dieses spezifischen Ansatzes bestehen - und damit zugleich auch vorbildlich aufzeigt, welche Fehltritte generell auf dem Weg narrativer Analysen von Paulustexten zu vermeiden sind: Grundsätzlich steht Hays dem Vorgehen Vias kritisch gegenüber, die Paulustexte in eine narrative Form „umzugestalten“ (,recasting of Paul's text into a narrative structure“). ${ }^{55}$ Überzeugend weist er nach: „[T]he attempt to fit Paul's discourse into a comic dramatic structure in the end distorts Paul's message." 56 Das Muster reiße auseinander, was bei Paulus klar zusammengehöre: Der Tod Christi sei nicht an völlig unterschiedlicher Stelle zu verorten als ,the world's pretensions ... shattering.“ Vielmehr sei dieses Erschüttern „Paul's interpretation of the event of the cross. “57 Hays schlussfolgert daher: „Via's scheme has forced him to factor out elements which are for Paul aspects of a single event and to project these elements into a narrative syntagm as separate events. “58

Überhaupt bemängelt Hays, dass Via keine Rechtfertigung seiner Methode im Hinblick auf das Wesen der Paulusbriefe biete. Der „comic view“ ist laut Via „more amenable than tragedy to a representation which is only semi-narrative. “59 Bedeutet dies, so fragt Hays, dass die Paulusbriefe „semi-narrative“ seien? Hinter dieser Unklarheit vermutet Hays als Ursache die generell laxe Verwendung des „genre“-Begriffs: Das „comic genre“ sei bei Via eine Art „super-genre, encompassing texts from a wide range of genres, texts which somehow manifest the death/resurrection (or upset/recovery) pattern."60 Dadurch würden aber die Paulusbriefe ihres partikulären Charakters beraubt. Hays formuliert daher um: „we may discern as a substructure in Paul's letters a Christ-story that has certain

52 Via, Kerygma, 66.

53 Hays, Faith, 69-70.

54 Hays, Faith, 69-70.

55 Hays, Faith, 67.

56 Hays, Faith, 67.

57 Hays, Faith, 67.

58 Hays, Faith, 67.

59 Via, Kerygma, 41.

60 Hays, Faith, 68. 
structural analogies to the plot-structure characteristic of Attic comedy. “61 Die Implikationen dieser Geschichte in den Paulusbriefen $\mathrm{zu}$ identifizieren, werde durch Vias großflächige Beschreibung eher erschwert als erleichtert. ${ }^{62}$ Hays nimmt hier mehrere zentrale Kritikpunkte vorweg, die auch gegenüber dem „narrative approach“ teilweise in Anschlag gebracht werden können, wenn man sie auf einer grundlegenderen Ebene bedenkt (vgl. v. a. Kapitel 17, Abschnitt 2-5).

\subsubsection{Die Verortung in der Neuauflage}

Wie der Titel schon vermuten lässt, stellt das Buch einen Beitrag zur Frage nach

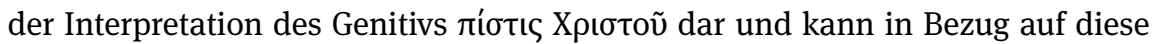
Diskussion als entscheidender Katalysator gelten. Nicht vernachlässigt werden darf jedoch auch der Untertitel des Werks: The Narrative Substructure of Galatians 3:1-4:11. Die große Wirkung der Arbeit ist auch daran zu erkennen, dass das Werk 2002 (also 19 Jahre nach seiner Erstveröffentlichung) als Teil der „Biblical Resource Series“ nachgedruckt wurde. Die von Hays verfasste ausführliche Einleitung $\mathrm{zu}$ dieser Neuauflage ${ }^{63}$ bietet nun auch einen verbesserten Zugang zur Verortung dieser Promotionsschrift innerhalb der Paulusforschung.

Hays betont gleich zu Beginn, dass trotz des Titels des Buches gelte, dass es

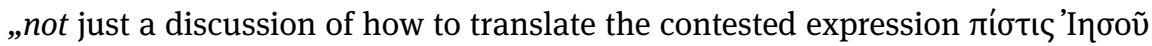

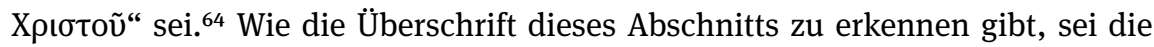
„Central Thesis“ seiner Arbeit nämlich vielmehr die „Narrative Substructure of Paul's Theology“ gewesen. ${ }^{65}$ Auch wenn der Untertitel des Buches sich konkret auf Gal 3,1-4,11 bezieht, wird in dieser Aussage nicht nur der über die Genitivkonstruktion hinausgehende Fokus, sondern, noch fundamentaler, das maßgebliche Anliegen Hays' überhaupt deutlich - nämlich, die grundsätzliche Struktur der paulinischen Theologie zu erforschen.

Betont wird dieser Fokus auch nochmals durch Hays' rückblickende Analyse seiner Interaktion mit dem Entwurf von Rudolf Bultmann:66 „Even where Bultmann is not mentioned explicitly, he is often the unnamed elephant in the room."67 Dabei war für Hays spezifischer die Reaktion gegenüber bestimmten Aspekten wichtig, die er bei Bultmann ausmachte: Zum einen habe dieser

61 Hays, Faith, 68.

62 Hays, Faith, 68.

63 Hays, „Introduction,“ xvi-lii.

64 Hays „Introduction,“ xxiii.

65 Hays „Introduction,“ xxiii.

66 Vgl. auch unten, Abschnitt 2.3.5 zum „battle.“ Vgl. auch oben, Kapitel 3, Abschnitt 6.2.

67 Hays, „Introduction,“ xxvi. Er nennt etwa die „laborious explanation of why I prefer to speak of ,story' and ,narrative' rather than ,myth' in Paul's thought-world.“ 
versucht „to ,de-narrativize“ Paul's thought world,“ zum anderen habe er das Evangelium verstanden ,principally as a message about human decision, human self-understanding. “68 Erneut fällt der umfassende Gegenstand der Hays'schen Untersuchung auf: die „Gedankenwelt“ des Apostels ist es, welche grundlegend narrativ strukturiert sei.

Natürlich definiert sich Hays’ Ansatz nicht nur in seinem Gegenüber. Vielmehr macht gerade die Einleitung zur Neuauflage deutlich, inwiefern Hays auf einem generellen Interesse anderer Forscher an narrativen Aspekten in der Theologie aufbaut. Primär ist hier sicherlich die Arbeit seines späteren Kollegen Hans Frei (1922-1988) zu nennen, welcher in The Eclipse of Biblical Narrative den Niedergang des Bewusstseins für Narrativität unter Bibelwissenschaftlern des 18. und 19. Jahrhunderts beklagt hatte. ${ }^{69}$ Wie Hays zusammenfasst: „Frei never attempted to apply his insights about narrative to Pauline texts, but his work provided the indispensable background for the question I was asking. “70

Auf eine unmittelbarere Weise als dies durch den von Frei maßgeblich mit ausgelösten Paradigmenwechsel in Bezug auf das Interesse nach narrativen Aspekten biblischer Texte der Fall war, ist darüber hinaus auf Leander E. Keck (1928-) hinzuweisen, bei welchem Hays 1978 ein Seminar über den Gebrauch von Traditionen bei Paulus belegt hatte. ${ }^{71}$ Wie Hays im 1981 verfassten Vorwort schreibt: „From ... Keck I acquired the vision for seeking to distinguish ,what Paul preached" from the particular matters at issue in his letters. “72

Nachdem wir bereits den Schlagworten der paulinischen „theology“ und der „thought world“ des Apostels begegnet sind, zeigt sich hier ein weiterer Aspekt, welcher für Hays' Analyse maßgeblich ist: Im Zentrum stehen erstens konkrete Texte, also die zu bestimmten Anlässen verfassten Briefe des Paulus und speziell - in seiner Dissertationsschrift - die formelhaften Passagen Gal 3,13-14 und 4,3-6 sowie der unmittelbare literarische Kontext (Gal 3,1-4,11).

Zweitens wird auch deutlich, dass es Hays bei der Analyse dieser schriftlichen Erzeugnisse des Apostels gerade darauf ankommt, die Realitäten ins Auge zu fassen, welche diesem Prozess der Niederschrift vorausgehen. Und dabei geht es Hays eben gerade nicht nur um eine abstrakte Gedankenwelt, die es um ihrer selbst willen zu rekonstruieren gelte. Vielmehr ist es die tatsächliche Verkündigung des Apostels, welche als Bindeglied zwischen dessen Weltbild und den uns zugänglichen schriftlichen Zeugnissen eine zentrale Rolle spielt.

68 Hays „Introduction,“ xxvi.

69 Frei, Eclipse.

70 Hays „Introduction, “ xxv.

71 Hays, Faith, xvii.

72 Hays, Faith, xvii. 
Schon aus dieser Verortung des Beitrags Hays' wird daher deutlich, dass der Gegenstand seiner Analyse letztendlich mehrere Ebenen betrifft. Die simple Aussage, dass Paulus „Briefe schreibe,“ zerfällt bei Hays in einen mehrstufigen Prozess: Es ist die narrativ strukturierte Gedankenwelt des Apostels, welche ihren Ausdruck findet in der narrativen Gestalt sowohl der mündlichen Verkündigung als auch der schriftlichen Texte. Die Aufgabe des Exegeten besteht demnach ganz grundsätzlich auch darin, individuelle Passagen in einen größeren narrativen Rahmen einzuordnen und auf diese Weise die paulinische Theologie zu rekonstruieren.

\section{3 ,Story' als narrative Substruktur}

\subsubsection{Zur grundsätzlichen Rolle des narrativen Elements}

Nachdem in Teil I dieser Arbeit (Kapitel 2, Abschnitt 2.3) bereits Hays' narrative Terminologie unter die Lupe genommen wurde, kann nun das Verhältnis der von ihm angenommenen „story“ zur paulinischen Argumentation, auf welche erstere Kategorie letztlich einwirken soll, genauer bestimmt werden. Hays betont nämlich ausdrücklich, dass die ,gospel story“ den Paulinischen Diskurs nicht determiniere, in dem Sinne, dass letzterer direkt und unausweichlich aus ersterer folge. ${ }^{73}$ Denn immerhin hält er die Möglichkeit offen, dass die Gegner des Apostels dieselbe Geschichte explizierten, aber eben dabei unterschiedliche Schlüsse aus ihr zögen. ${ }^{74}$

Doch was bedeutet dieser Einfluss dann positiv formuliert? Zum einen stelle diese Geschichte die fundamentalen Substrukturen zur Verfügung, auf welchen die paulinische Argumentation aufgebaut sei. Zum anderen würden auf diese Weise auch bestimmte Begrenzungen („,boundaries or constraints“) für die Logik des paulinischen Diskurses bereitgestellt. ${ }^{75}$ Anstatt des Schlagwortes „Determination“ bevorzugt Hays daher die Bezeichnung dieser Geschichte als ,integral“ für den Gedankengang des Apostels. ${ }^{76}$ Im Vergleich zum Anliegen Bekers ${ }^{77}$ gehe es ihm nicht so sehr darum, den Prozess aufzuzeigen, durch welchen der Kern des Evangeliums in Verbindung mit konkreten Situationen der paulinischen Gemeinde trete, sondern darum, diesen Kern selbst genauer zu bestimmen - der,

73 Hays, Faith, 7.

74 Hays, Faith, 7.

75 Hays, Faith, 7.

76 Hays, Faith, 7.

77 Beker, „Contingency and Coherence,“ 135. 
laut Hays, bei Beker sehr allgemein bleibe, weil er in generellen Phrasen über den kosmischen Triumph Gottes beschrieben werde. ${ }^{78}$

\subsubsection{Erste Einschränkung: Die Ebene des Mentalen}

An diese Überlegung zum Verhältnis von narrativen Elementen und paulinischer Argumentation lassen sich weitere Aspekte anschließen, die sich bei Hays an verschiedenen Stellen seines Buches finden. Auch in der Zusammenschau ergeben sie allerdings eher ein fragmentarisches Bild, da sie größtenteils in Abgrenzung zu einer Auswahl anderer Konzepte, die auf die ein oder andere Weise mit dem von ihm gemachten Vorschlag in Spannung stehen, formuliert werden.

Wichtig ist in dieser Hinsicht vor allem eine lokale Spezifizierung, die Hays im Dialog mit Stephen Crites, P. Ricœur und J. D. Crossan vornimmt. ${ }^{79}$ Es gehe ihm nicht um allumfassende Behauptungen einer narrativen Struktur des menschlichen Bewusstseins im Allgemeinen, in dem Sinne, dass wir als Menschen durch unser Erleben der Zeit immer „in einer Geschichte“ lebten. Hays tritt sogar in einen, für viele Leser sicherlich überraschenden, Widerspruch zu dieser Position: Es sei gerade der springende Punkt seiner These, dass das Denken des Paulus von einer Geschichte geprägt sei, wie es für das Denken im Allgemeinen eben nicht gelten könne.

Die Frage, ob der Argumentation des Paulus eine bestimmte Geschichte zu Grunde liege, sei also grundverschieden von dieser grundsätzlicheren Überlegung. Ja, der Sinngehalt der ersteren wäre sogar in Zweifel gezogen, ${ }^{80}$ wenn jeglicher Diskurs letztendlich nur eine Instanziierung narrativer Strukturen wäre. In dieser Hinsicht ist Hays recht weit entfernt vom narrativen Paradigma, das Fisher kurz darauf entwickeln sollte (vgl. hierzu Kapitel 9, Abschnitt 3.2). Selbst im Hinblick auf Paulus allein geht es Hays explizit nicht um den Ursprung der narrativen Muster, welche er in den Briefen des Paulus ausmacht. ${ }^{81}$

\subsubsection{Zweite Einschränkung: Die Ebene des Briefes}

Hays ist es zudem wichtig, dem Missverständnis vorzubeugen, dass seine Untersuchung die nicht-narrativen Elemente in den Paulus-Briefen entweder

78 Hays, Faith, 7-8.

79 Crites, „Narrative Quality“; Ricœur, „Narrative Function“; Crossan, Theology of Story.

80 Des Weiteren verweist Hays, Faith, 20-21 darauf, dass er entgegen Crossan durch den Verweis auf die Bedeutung von Geschichten - bzw. eben der bestimmten Jesus-Geschichte für Paulus nicht die Beliebigkeit koexistierender narrativer Entwürfe voraussetzen wolle.

81 Hays, Faith, 21. 
herunterspielen oder gar leugnen wolle. ${ }^{82}$ Seine Formulierung ist dabei recht nahe an dem, was Kritiker/-innen des narrativen Ansatzes zuweilen vorbringen: „The letters are, after all, letters, and their form is certainly influenced by epistolary and rhetorical conventions. "83 Darüber hinaus gebe es, selbstverständlich, auch Abschnitte (er verweist auf das „halachische“ Material in 1 Kor 7), welche auf keine erkennbare Weise mit narrativen Substrukturen verbunden seien. ${ }^{84}$

Die Versicherung, dass natürlich kein Anspruch erhoben werde, überall in den paulinischen Briefen zugrundeliegende narrative Strukturen identifizieren zu wollen, führt zu einer weiteren Einschränkung in Bezug auf das „Wo?,“ die auch schon in der Auseinandersetzung mit Robert Funk ${ }^{85}$ anklingt: Konkret geht es Hays darum, aufzuzeigen, dass eine „gospel story“ grundlegend sei für die explizit theologischen Anteile des paulinischen Diskurses, speziell die Passagen in welchen der Apostel versuche, die fundamentalen „features of his proclamation“ $\mathrm{zu}$ artikulieren. ${ }^{86}$ Konkreter wählt Hays den Galaterbrief, da Paulus in diesem aufgrund der Situation, in welcher er sich befand, gezwungen gewesen sei, den grundsätzlichen Inhalt seiner Botschaft $\mathrm{zu}$ verteidigen. ${ }^{87}$ Daher sei zu erwarten, dass sich hinter den „kerygmatic summaries“ Verweise auf seine Verkündigung als Ganzes identifizieren lassen. ${ }^{88}$

\subsubsection{Von der Lokalisierung zum Inhalt}

Diese Beschränkung auf die Kategorie der „story“ als Inhalt der paulinischen Verkündigung und das Ausklammern anderer Ebenen führt auch zu einer wichtigen Spezifizierung im Hinblick auf den Inhalt dieser Geschichte. Wie bereits die bisherige Betrachtung zeigt, spricht Hays häufig generell von einer „gospel story,“ aber auch - konkreter - von einer „Jesus story.“

Dieser Aspekt nimmt erstaunlich wenig Raum in Hays' methodischen Vorüberlegungen ein. Möglicherweise deshalb, da sich dieser Fokus für ihn aus der inhaltlichen Analyse der zugrundegelegten Galater-Texte ergibt. Zweifellos liegen

82 Hays, Faith, 8.

83 Hays, Faith, 8.

84 Hays, Faith, 8.

85 Funk, Language.

86 Hays, Faith, 9. Siehe auch später (Hays, Faith, 22): „... the theological portions of Paul's letters ...“"

87 Hays, Faith, 73. Siehe auch Hays, Faith, 29.

88 Hays, Faith, 29. 
aber auch schon im Hinblick auf die Auswahl dieser untersuchten Texte weichenstellende methodologische Voraussetzungen vor. ${ }^{89}$

Von daher ist es durchaus erwähnenswert, dass Hays diesen Fokus in Dialog mit Leander Keck entwickelt (siehe zu den Hintergründen oben, Abschnitt 2.2.2): Dieser ging davon aus, dass Paulus bei der Entfaltung seiner Argumente auf seine vorhergehende Predigt und Unterweisung anspiele (,alludes“): „The letters do not summarize what Paul preached to elicit faith, but interpret aspects of that preaching and its foundations."90 Soweit ließe sich diese These interessanterweise auch noch aus den „Entlastungen“ der hier untersuchten expliziten Narrationen (siehe Kapitel 8, v. a. Abschnitt 2 und 3) begründen.

Hays geht insofern über diese Position hinaus, dass er vorschlägt, dass dieser Inhalt der paulinischen Predigt „a story of Jesus Christ“ gewesen sei und dass das paulinische Evangelium daher eine narrative Struktur gehabt hätte. ${ }^{91}$ Später bemerkt er noch explizit, dass er im ausgewählten Galater-Text nach der Struktur der „gospel story“ suche und nicht nach der von „Paul's personal story“ in Gal 1,12-2,14, wie sie durch die rhetorische Analyse von Betz ins Zentrum gerückt worden sei. ${ }^{92}$ Selbst Hays zeigt sich hier - wenn auch in der Abgrenzung zu einer anderen, von ihm nicht verfolgten „story“ - also von der Engführung des Erzählungs-Konzepts innerhalb der rhetorischen Kritik auf narrationes stark beeinflusst (vgl. Kapitel 1, Abschnitt 2.2.2).

\subsection{5 ,Story' und ,Argument'}

Die Klärung der materialen Basis der Suche nach „narrativen Substrukturen“ bei Paulus muss außerdem ergänzt werden durch eine Klärung der Frage vom Verhältnis von Narrativität zum analysierten „reflective discourse.“ Hays stellt sich diesem Problem, indem er selbst die Frage aufwirft, ob es überhaupt Sinn mache, zu sagen, dass eine Geschichte (,story“) als eine Beschränkung (,constraint“) für die Logik eines Arguments (,argument“) fungieren könnte.

Für ihn kommen in dieser Hinsicht ein Argument „illustrierende“ Erzählungen gerade nicht in Frage, da sie letztlich ersetzbar und damit ohne eigentlichen Beitrag zum Diskurs seien (vgl. oben, Kapitel 2, Abschnitt 4). ${ }^{93}$ Die Substrukturen, die Hays im Blick hat, ließen sich vielmehr daran erkennen, dass sie $z w e i$

89 Vgl. Insbesondere unten, Kapitel 17, Abschnitt 3 zur zweifelhaften Synthese von impliziten Erzählungen auf der Grundlage einer vorausgesetzten Erzählfigur und Kapitel 17, Abschnitt 5.6 zur Frage nach der „Vorlage.“

90 Keck, Paul, 31.

91 Hays, Faith, 8.

92 Hays, Faith, 30.

93 Hays, Faith, 22. 
Bedingungen erfüllten: Sie seien zum einen nicht direkt an der Textoberfläche ablesbar (Hays spricht von einer ,story that may find only allusive, fragmentary expression within the discourse“), ${ }^{94}$ zum anderen gelte aber auch, dass ohne diese Geschichten der Diskurs unverständlich bleiben müsse, weil gilt: „[T]he discourse exists and has meaning only as an unfolding of the meaning of the story. “95

Eine grundsätzliche Voraussetzung für die positive Evaluierung des genannten Verhältnisses sei also die Annahme, dass diskursive Sprache und ,the language of story“ in einem organischen - und nicht künstlichen - Verhältnis zueinander stünden. ${ }^{96} \mathrm{Zu}$ diesem Zweck stellt Hays einige Überlegungen des Literaturwissenschaftlers Northrop Freye, des Philosophen Paul Ricœur und des Bibelwissenschaftlers Robert Funk zusammen. ${ }^{97}$ Im Rückblick schreibt er zu diesem Vorgehen durchaus selbstkritisch: ${ }^{98}$

In order to fight this battle [d. h.: mit Bultmanns Paradigma] I enlisted the aid of whatever methods came to hand ... I cobbled together an eclectic assemblage of insights from various critics ... No one of these critics provided a comprehensive methodological framework, but each contributed something significant to my proposal about how reflective theological discourse can be grounded in a narrative substructure.

Funk ${ }^{99}$ dient vor allem als Kronzeuge für die Idee des paulinischen Sprechens als „reflective upon the language deposit left by previous reflection." 100 Dementsprechend konkretisiert Hays: „Paul is reviewing the destiny of a story about Jesus Christ which is expressed most clearly in the hymnic and confessional passages of the letters." ${ }^{101}$ Für die spezifische These, dass auch in argumentativen Passagen durch Anspielung auf „key events of the story“102 diese Geschichte aufgerufen werde, benötigt Hays jedoch ein theoretisches Fundament, das Funk selbst nicht liefert.

Den entscheidendsten Beitrag scheint für Hays Northrop Fryes Verständnis von „mythos“ und „dianoia“ zu liefern. ${ }^{103}$ Aus diesem leitet er ab, dass es eine organische Beziehung zwischen dem auch nicht-narrativ ausdrückbaren Thema

\footnotetext{
94 Hays, Faith, 22.

95 Hays, Faith, 22.

96 Hays, Faith, 21.

97 Hays, Faith, 22-29.

98 Hays, „Introduction,“ xxvi.

99 Funk, Language.

100 Funk, Language, 232.

101 Hays, Faith, 27.

102 Hays, Faith, 28.

103 Siehe v. a. Frye, Anatomy.
} 
einer Erzählung und dessen Plot gebe. ${ }^{104}$ In der Zusammenfassung des Ertrags aus der Analyse der genannten Beiträge kann er vor diesem Hintergrund behaupten, dass es bei der Betrachtung von „reflective discourse“ demnach möglich sei, „to inquire about the story in which it is rooted."105

Einen ähnlichen Zusammenhang von „sequence“ und „pattern“ sieht Hays in Ricœur's Gegenüberstellung einer „chronologischen“ und einer „nichtchronologischen“ Dimension von Erzählungen. ${ }^{106}$ Hays scheint aber gerade im Hinblick auf Ricœur die eigentliche Frontstellung massiv zu verkennen und es ist daher äußerst zweifelhaft, ob es gerechtfertigt ist, auf dieser Basis von einer „rearticulat[ion] in discursive language [of] the configurational dimension of the gospel story“ zu sprechen. ${ }^{107}$

Denn Hays scheint zu übersehen, wie Ricœur die Bezeichnung einer mentalen Operation als „configurational“ von Louis Mink übernimmt. ${ }^{108}$ Für Mink gibt es „three modes of comprehension,“ welche es ermöglichten „,in a single mental act“ Dinge zu erfassen, ,which are not experienced together, or even capable of being so experienced, because they are separated by time, space, or logical kind.“109 Der „configurational mode“ zeichne sich nun dadurch aus, dass er Dinge als Elemente eines einzigen zusammenhängenden Komplexes an Beziehungen ausweist. Interessanterweise wird dadurch der Aspekt der Narrativität gerade eingeführt - der Akt des Verbrennens eines Briefes etwa wird letztendlich als Teil einer größeren narrativen Struktur verständlich:110

As a letter, it belongs to a kind of story, a narrative of events which would be unintelligible without reference to it. But to explain this, I would not construct a theory of letters or of friendships but would, rather, show how it belongs to a particular configuration of events like a part of a jigsaw puzzle.

Ricœur wiederum übernimmt die Terminologie nun in einem sehr spezifischen Kontext, nämlich um ,anti-narrative arguments directed against an epistemology of history based on the phenomenology of following a story" zu widerlegen. ${ }^{111}$ (Man darf nicht vergessen, dass das grundlegende Anliegen des Essays ist, eine

104 Hays, Faith, 28.

105 Hays, Faith, 28. Hervorhebung nicht im Original.

106 Hays, Faith, 27, der Riceour, „Narrative Function“ bespricht.

107 Hays, Faith, 25.

108 Ricœur, „Narrative Function,“ 278.

109 Mink, „History,“ 547.

110 Mink, „History,“ 551.

111 Ricœur, „Narrative Function,“ 278. Hervorhebung nicht im Original. 
umfassende Theorie narrativen Diskurses zu entwerfen, die sowohl „historical“ als auch „fictional narratives“ umschließt. ${ }^{112}$ )

Hays erkennt richtig, dass bei Ricœur mit diesem Konzept ausgesagt wird, dass ,the ,configuration“ of narrative elements into significant patterns ... integral to the narrative itself rather than imposed upon it from outside" sei. ${ }^{113}$ Gegen die Kritiker/-innen einer narrativen Herangehensweise an Geschichte hält Ricœur nämlich fest, dass Erzählungen eben nicht nur in aneinandergereihten Episoden bestünden: „[T]he activity of narrating ... also constructs meaningful totalities out of scattered events. “114

Damit ist aber gerade nicht gesagt, dass man reflektiven Diskurs bei Paulus verstehen könne ,as growing organically out of the process of narration. "115 Denn es gilt laut Ricœur nicht nur, dass eine Erzählung zwangsläufig mehr ist, als nur Sequenz, sondern auch „that the configurational dimension cannot eclipse the episodic dimension without abolishing the narrative structure itself." 116 Vor diesem Hintergrund kritisiert Ricœur dann explizit Greimas dafür, dass er den Plot auf die Ebene der Oberflächenstruktur verlagere. ${ }^{117}$ Eine solche De-Chronologisierung sei aufgrund des „irreducibly sequential element of the narrative“ nicht möglich. ${ }^{118}$

Damit ist natürlich nicht gesagt, dass es unmöglich wäre, die besagte „Konfiguration“ der Erzählung nicht-narrativ zum Ausdruck zu bringen. Es wurde, im Gegenteil, bereits oben (Kapitel 5, Abschnitt 3.4) beispielsweise auf die Möglichkeit verwiesen, dass modal-instrumentale Konnexionen Sachverhalte aus Erzählungen aufgreifen und ohne temporalen Fokus zum Ausdruck bringen können. Hays' Rückgriff auf Ricœur muss aber dennoch als sehr problematisch gelten. Denn zwischen der von Hays postulierten „organic relationship“ und der von Ricœur für denselben Vorgang gebrauchten Rede vom „abolishing [!] the narrative structure“ besteht doch eine gravierende Distanz.

\subsubsection{Narrative Logik}

Wie sich Hays die Beziehung zwischen narrativer Substruktur und nichtnarrativem Diskurs vorstellt, wird dann insbesondere auch in seiner Exegese zu Gal 3,1-4,11 deutlich. Hier ist die Beobachtung wichtig, dass Hays bei der

112 Ricœur, „Narrative Function,“ 274.

113 Hays, Faith, 24.

114 Ricœur, „Narrative Function,“ 278.

115 Hays, Faith, 25.

116 Ricœur, „Narrative Function,“ 279. Hervorhebung nicht im Original.

117 Ricœur, „Narrative Function,“ 281.

118 Ricœur, „Narrative Function,“ 282. Für das Argument siehe v. a. Ricœur, „Narrative Function," 285. 
Rekonstruktion des Gedankengangs dieses Abschnitts davon ausgeht, dass im Hintergrund die Verkündigung des Apostels von der Treue Jesu steht. Paulus folge beim Schreiben des Abschnitts also einer „narrativen Logik.“

Diese setzt sich ab von anderen Konzeptionen wie der einer ,juristischen,“119 einer „rabbinischen“120 oder einer „rhetorischen“121 Logik. Der letztgenannte Ansatz, wie er etwa von Betz vertreten wird, sieht Gal 3,1-4,11 als Teil der sich von 3,1 bis 4,31 erstreckenden probatio, wobei davon ausgegangen wird, dass die in diesem Zuge vorgebrachten Argumente untereinander kaum verbunden seien, sondern ihre Einheit lediglich in Bezug auf das gemeinsame Anliegen hätten. ${ }^{122}$

Wie ist diese narrative Logik nun konstruiert? Hays grenzt sie von einer propositionalen Logik $\mathrm{ab}$, in welcher Konsequenzen notwendigerweise aus Prämissen folgten. ${ }^{123}$ Demgegenüber seien Geschichten durch eine „chronological sequence“ geprägt. ${ }^{124}$ Dementsprechend kann die (I) narrative Abfolge („sequence“) als strukturierendes Element dienen, etwa wenn auf das chronologische Element, das in der Metapher des Erbes inhärent ist, hingewiesen wird. ${ }^{125}$

Auch wenn ihnen zwar das Element der logischen Notwendigkeit fehle, so gelte allerdings trotzdem, dass diese Ereignisse nicht zufällig verbunden seien: „they must bear a certain relation to one another so that the entire story can be perceived as a unity." ${ }^{126}$ Die Kohärenz von Ereignissen in Narrativen sei daher dadurch charakterisiert, dass sie sich an „fitness rather than ... logical necessity“ orientiere. ${ }^{127}$ Aus der Perspektive der erzähltheoretischen Annäherung an das Konzept der ,Erzählung، (vgl. Kapitel 3, Abschnitt 3.4) scheint Hays damit neben dem Aspekt der temporalen Verknüpfung von Ereignissen (s. o., „sequence“) auch die Wichtigkeit weiterer sinnhaften Verbindungen eingefangen zu haben. ${ }^{128}$

119 Hays, Faith, 184-189 mit Verweis auf Taylor, „The Function.“ 120 Hays, Faith, 189-192 mit Verweis auf Dahl, „Contradictions.“

121 Hays, Faith, 192-194.

122 Vgl. Betz, Galaterbrief, 54-72. Die in dieser Arbeit aus narratologischer Perspektive gebotenen Tiefenbohrungen an einigen Stellen in diesem Abschnitt entwerfen ein vollkommen anderes Bild. Es zeigt sich hier eindrücklich, wie fatal die Limitierung der Wahrnehmung von Narrativität in den Paulusbriefen auf den Rahmen der „rhetorischen Kritik“ wäre. Siehe hierzu oben, Kapitel 1, Abschnitt 2.2.2.

123 Hays, Faith, 195.

124 Hays, Faith, 195.

125 Vgl. Hays, Faith, 195 mit 197. Siehe zu Gal 4,1-12 oben, Kapitel 9, Abschnitt 5 und im Hinblick auf Substrukturen vor allem unten, Kapitel 16, Abschnitt 3.

126 Hays, Faith, 195.

127 Hays, Faith, 195.

128 Vgl. auch oben, Kapitel 9, Abschnitt 3.2 zu Fisher. 
Hays' eigene Darstellung nimmt jedoch eine andere Unterscheidung vor: Er subsumiert die im letzten Abschnitt skizzierte doppelte „fitness“ unter dem Aspekt der Sequenz und setzt diese mit Ricœurs „episodic dimension“ gleich. Davon grenzt er dann Ricœurs „configurational dimension“ ab - obwohl sich wohl mit gutem Recht behaupten ließe, dass diese sehr passgenau mit der Konzeption der sinnhaften Verbindungen übereinstimmt, insofern sich hierin gerade die Beziehung der Ereignisse auf den Plot ausdrücken. ${ }^{129}$

Wenn Hays nun der Sequenz ein „Muster“ gegenüberstellt, so scheint er damit eine semantische Größe einzuführen: Die von einer Erzählung gesetzten „patterns of order and value“ 130 bezeichnet Hays in Abgrenzung zur Sequenz als (II) Gestalt (,shape“) der Geschichte und bringt dieses Konzept mit Fryes ,dianoia“ in Verbindung. Auch hier spielen Ursache-Wirkungs-Verknüpfungen eine Rolle, doch was Hays vor Augen hat, ist offensichtlich inhaltlich bestimmt: ${ }^{131}$

Certain networks of relationship among characters are established, and effects follow from some specified causes rather than from others.

Auch diese narrative Gestalt könne Diskurs prägen, da die Muster von identitätsstiftenden Geschichten eine „prescriptive-ethical“ Signifikanz bekommen können. ${ }^{132}$ Die Angemessenheit einer Aktion könne daran bemessen werden, inwiefern sie zu einem bestimmten narrativen Muster passe. ${ }^{133}$ Die partizipationistische Soteriologie des Abschnitts sieht Hays damit verbunden: ,the action of Jesus Christ in the gospel story defines the pattern of justification and life." ${ }^{134}$ Das Argument in Gal 3,1-4,11 findet somit sein kohärenzstiftendes Element ,in the story of the Messiah who lives by faith. “135

\section{N. T. Wright}

\subsection{Vorbemerkung}

Ist in Bezug auf Hays dessen grundsätzlicher Beitrag zu einem verstärkten narrativen Fokus auf Paulus aufgrund des expliziten Themenschwerpunktes seiner

\footnotetext{
129 Vgl. Ricœur, „Narrative Function,“ 277.

130 Hays, Faith, 195.

131 Hays, Faith, 195.

132 Hays, Faith, 195.

133 Hays, Faith, 195.

134 Hays, Faith, 206.

135 Hays, Faith, 207.
} 
Dissertation leicht ersichtlich und zusammenzufassen, so steht man bei N. T. Wright vor dem Problem, dass dessen Anteil an der gegenwärtigen Beliebtheit des „narrative approach“ in manchen Kreisen zwar sicherlich vergleichbar groß, aber doch deutlich schwerer $\mathrm{zu}$ fassen ist.

Dies liegt schon am Umfang seiner Forschung zu Paulus, welche neben seiner unveröffentlichten Dissertation ${ }^{136}$ vor allem zwei große Aufsatzbände, ${ }^{137}$ Kommentare sämtlicher Briefe des corpus Paulinum auf populärem ${ }^{138}$ sowie zum Römer- und Kolosserbrief auf akademischem Niveau, ${ }^{139}$ mehrere kleinere Monographien zur Theologie des Apostels, ${ }^{140}$ eine paulinische Forschungsgeschichte ${ }^{141}$ und natürlich das große Werk Paul and the Faithfulness of God ${ }^{142}$ umfasst. $^{143}$

Wright bringt nicht an einer Stelle eine spezifische textbasierte These zur Bedeutsamkeit von Narrativität bei Paulus vor. Sie ist vielmehr eine vielschichtige Größe, auf welche Wright in seiner Arbeit konstant Bezug nimmt. Dieser Umstand bildet den Hintergrund dafür, dass Barclay etwas frustriert kommentiert: ${ }^{144}$

\footnotetext{
[C]laims for the significance of „story“ within Pauline theology have become both conceptually more diffuse and materially more specific. N. T. Wright, for instance, employs the category of „story“ in an enormous variety of ways while simultaneously making the highly specific claim that the narrative structure of the New Testament, including Pauline theology, is essentially the Jewish story, now „redrawn“ around Jesus.
}

Es wird noch zu sehen sein, inwiefern Wright tatsächlich ein variableres Konzept von Narrativität verwendet, als dies etwa Hays tut (siehe unten, Abschnitt 4) und ob letztlich nicht auch Barclays eigenes Vorgehen Wright erstaunlich nahesteht (vgl. Kapitel 17, Abschnitt 3.1).

Zunächst soll aber im Folgenden der Versuch unternommen werden, eine Skizze der Wright'schen Konzeption zu erstellen, die überwiegend von den grundlegenden Überlegungen in The New Testament and the People of God ausgeht und die von Barclay wahrgenommene Vielfalt systematisiert, wobei eklektisch auf andere Arbeiten verwiesen wird, wo Einzelaspekte durch diese besonders erhellt werden.

136 Wright, „Messiah.“

137 Wright, Climax und Pauline Perspectives.

138 Für Paulus siehe die Bände Paul for Everyone.

139 Wright, Epistles und „Romans.“

140 Z. B. Wright, Justification, What St Paul Really Said und Fresh Perspective.

141 Wright, Interpreters.

142 Wright, Faithfulness.

143 Vgl. auch Bird, Heilig und Hewitt, „Introduction,“ 3-4.

144 Barclay, „Paul’s Story,“ 134. 


\subsection{Narrative Strukturen und Erkenntnis}

Wie auch immer man den exegetischen Ertrag der Arbeit Wrights beurteilt, muss man doch wohl eingestehen, dass er sich wie kaum ein Neutestamentler der Gegenwart seit Bultmann darum bemüht hat, die hermeneutischen Voraussetzungen seines Projekts offenzulegen. ${ }^{145} \mathrm{Zu}$ Beginn des ersten Bandes seiner Reihe Christian Origins and the Question of God, also in The New Testament and the People of God (1992), ${ }^{146}$ verwendet Wright die ersten 150 Seiten auf die Spezifikation der Aufgabe und Methodologie seines Projektes. ${ }^{147}$

Grundlegend ist dabei seine - durchaus als eigenständig zu würdigende ${ }^{148}$ Version eines kritischen Realismus, welcher zum einen „the reality of the thing known as something other than the knower" postuliert, aber diesen Zugang zum anderen als ,along the spiraling path of appropriate dialogue or conversation between the knower and the thing known" verlaufend lokalisiert. ${ }^{149}$

Das Wesen dieses Dialogs wird dann direkt im Anschluss durch narrative Kategorien expliziert. Sehr prägnant kann Wright vor dem Hintergrund seiner Erörterungen später sagen: „All knowledge proceeds by the telling of new stories."150 Wie dieser Prozess genau abläuft und wie diese Rekonstruktion aus erkenntnistheoretischer Sicht zu bewerten ist, wurde an anderer Stelle im Detail erörtert. ${ }^{151}$ Hier soll nur in sehr groben Zügen der Aspekt der Narrativität nachgezeichnet werden.

Ausgangspunkt des besagten Erkenntnisfortschritts ist stets eine Beobachtung, ein Ereignis, das sich von unseren Erwartungen abhebt, etwa ein merkwürdiges Geräusch beim Autofahren. ${ }^{152}$ Als bemerkenswert zeichnet es sich natürlich gerade dadurch aus, dass es sich abhebt von dem, was unsere Standard-Erzählung darüber ist, wie eine Autofahrt normalerweise verläuft. Um mit der unerwarteten Beobachtung umzugehen, bilden wir Hypothesen. Wir versuchen zu erklären, was sich ereignet hat, sodass wir nun dieses merkwürdige Geräusch vernehmen. Erklärungen sind nun nach Wright - und in Übereinstim-

\footnotetext{
145 Vgl. entsprechend auch die Wertschätzung durch Wischmeyer, „Biblical Hermeneutic.“ 146 Wright, New Testament.

147 Wright, New Testament, 1-145.

148 Losch, „Critical Realism.“

149 Wright, New Testament, 35.

150 Wright, New Testament, 113.

151 Heilig und Heilig, „Historical Methodology.“ Siehe dort für Details zu den hier sehr grob zusammengefassten Eckpunkten.
}

152 Wright, New Testament, 42-43. 
mung mit aktueller wissenschaftstheoretischer Entwürfen - Geschichten über kausale Zusammenhänge. ${ }^{153}$

Wrights methodischer Ansatz im Hinblick auf die Erforschung der Vergangenheit kann gut mit Hilfe der (von ihm auch selbst gewählten) wissenschaftstheoretischen Kategorie der ,Abduktion“ expliziert werden. ${ }^{154}$ Dass für ihn hierbei jedoch mehr involviert ist als lediglich eine pragmatische Vorgehensweise des Forschens, wird schon daran deutlich, dass er auch sämtliche Aspekte des Testens von Hypothesen in narrativer Terminologie expliziert: Konkurrierende Geschichten (über geplatzte Reifen, Straßenschäden etc.) werden anhand verschiedener Kriterien auf Plausibilität hin geprüft, unter anderem anhand der Frage, wie sie sich zu anderen Geschichten verhalten (Vorgeschichte der Reifen, Beobachtungen von Bauarbeitern während der Fahrt etc.). „Erzählungen“ sind also ganz eindeutig auf grundlegende Weise mit menschlichem Wahrnehmungsvermögen und Bewusstsein verbunden.

\subsection{Narrative Strukturen und Weltanschauungen}

Hier kommt Wrights Kategorie des „worldview“ ins Spiel. Damit meint er nur ansatzweise, was im Deutschen an diffusen Aspekten mit der Kategorie der ,Weltanschauung، gemeint ist. Wright geht es nicht einfach nur, wie in einem gängigen Alltagsverständnis üblich, um die „Menge von zusammenhängenden, aber rein persönlichen Meinungen über die ,letzten Fragen. ““155 Das von ihm ins Auge gefasste Konzept lässt sich jedoch auch nur schwer philosophiegeschichtlich einordnen, wie die folgende Skizze darzustellen versucht.

Da Wright im ,worldview` explizit eine auf Gesellschaften bezogene Größe sieht ${ }^{156}$ und sie auf eine ,presuppositional, pre-cognitive“ Ebene bezieht, ${ }^{157}$ ließe sich am ehesten eine Verbindung zu Schelers Konzept der ,Weltanschauung` als „Name für die organisch und geschichtlich gewordene Art und Weise großer zusammenhängender Gruppen, Welt, Seele und Leben tatsächlich anzuschauen und zu werten“ herstellen. ${ }^{158}$ Insofern hierbei die natürliche Weltanschauung (im Gegenüber zu einer Bildungsweltanschauung) in den Blick genommen wird, ist

153 Siehe die ausführliche Diskussion bei Lipton, Inference.

154 Siehe Heilig und Heilig „Historical Methodology.“

155 Thomé, „Weltanschauung,“ 457.

156 Wright, New Testament, 122.

157 Wright, New Testament, 122.

158 Scheler, Schriften, 7. 
damit genau das gemeint, was innerhalb einer Gruppe „als keines Beweises ... bedürftig geglaubt und gefühlt wird."159

Damit ist etwas umrissen, was im Gefolge Diltheys als das „durch den von außen hinzutretenden Interpreten aus Dokumenten und ,Lebensspuren“ [R]ekonstruiert[e]“ mit dem Terminus des „Weltbilds“ bezeichnet wird. ${ }^{160}$ Auch diese Benennung ist jedoch problematisch, insofern damit teilweise, etwa im Sinne Fichtes auf ein Konzept verwiesen wird, das sich von dem der ,Weltanschauung“ dadurch abhebt, dass es dessen Produkt darstellt. ${ }^{161}$ Wright betont demgegenüber viel mehr die Funktion eines „worldview“ als eines vorgelagerten Interpretationsrahmens für das Betrachten der Welt: ${ }^{162}$

Worldviews ... are like the foundations of a house: vital, but invisible. They are that through which, not at which, a society or an individual normally looks; they form the grid according to which humans organize reality, not bits of reality that offer themselves for organization.

Im Folgenden wird mangels besserer Alternativen die Bezeichnung der „Weltanschauung“ verwendet, dabei aber konkret vorausgesetzt, was hier umrissen wurde. Dieses Übersetzungsäquivalent wird auch verwendet, wenn Wright von einem „mindset“ als der individuellen Ausprägung eines „worldview“ einer größeren Gruppe spricht. ${ }^{163}$

Insofern Schellers „Weltanschauungen“ als kulturelle Muster verstanden werden, wird dadurch auch ein Schwerpunkt der Kulturwissenschaften vorweggenommen. ${ }^{164}$ Hierzu passt gut, dass Wright in der Einführung seiner eigenen Konzeption explizit auf soziologische Ansätze verweist. ${ }^{165}$ Auffällig ist dabei, dass Wright eine umfassendere Konzeption beschreibt als etwa Geertz, auf den er aufbaut. Dieser unterscheidet zwischen „ethos“ und „world view“:166

159 Scheler, Schriften, 16.

160 Thomé, „Weltbild,“ 461.

161 Thomé, „Weltbild,“ 461.

162 Vgl. neuerdings Wright, Faithfulness, 28: „We may remind ourselves that a ,worldview“ is not what you normally look at, but what you normally look through. (This is where the metaphor of „sight“ retains some use.) What we are now discussing is not the sort of thing humans habitually talk about or consciously engage in, but the sort of thing they habitually presuppose as they talk about, or consciously engage in, other subjects and activities.“

163 Eine Differenzierung im Deutschen ist schwierig, da etwa „Denkweise“ zu sehr auf den Modus des Nachdenkens verweist und „Mentalität“ zu sehr die Konnotation von Charaktereigenschaften evoziert.

164 Thomé, „Weltanschauung,“ 458.

165 Wright, New Testament, 122.

166 Geertz, Interpretation, 127. 


\begin{abstract}
A people's ethos is the tone, character, and quality of their life, its moral and aesthetic style and mood; it is the underlying attitude toward themselves and their world that life reflects. Their world view is their picture of the way things in sheer actuality are, their concept of nature, of self, of society.
\end{abstract}

Bei Wright verschmelzen die beiden Konzepte zu einer Einheit:167

Worldviews are the basic stuff of human existence, the lens through which the world is seen, the blueprint for how one should live in it, and above all the sense of identity and place which enables human beings to be what they are.

Auch wenn Weltanschauungen normalerweise „unsichtbar“ seien (s. o.), bedeutet dies nach Wright nicht, dass sie der Analyse vollkommen unzugänglich bleiben müssten. Denn die Tatsache, dass sie in Interpretation der und Reaktion auf unsere Umwelt von so fundamentaler Bedeutung sind, bedeutet, dass sie alltäglich als „sets of beliefs and aims“ an die Oberfläche treten. ${ }^{168}$

Spezifischer differenziert Wright im Anschluss zwischen grundsätzlichen „basic beliefs,“ welche sich in konkreteren „aims“ (also „Zielen“) niederschlagen, auf der einen Seite und, aus den „basic beliefs“ abgeleiteten, „consequent beliefs," welche in den spezifischen ,intentions“ sichtbar würden, auf der anderen Seite. Auf diese Weise ist daher das Handeln von Personen in der Geschichte immer auch Ausdruck von Weltanschauungen. Deren Rekonstruktion vermag laut Wright daher zu erklären, weshalb Menschen auf spezifische Weise gehandelt hätten.

Analytisch zugänglich sind diese Weltanschauungen letztlich durch vier interagierende Phänomene: Fragen, die sich Menschen stellen, Symbole, die ihren Alltag bestimmen, die Praxis ihres Handelns - und eben Erzählungen. ${ }^{169}$ Folgende Darstellung bringt dies auf den Punkt (Abb. 58). ${ }^{170}$

Zwar betont Wright, dass diese vier Parameter nicht weiter reduzierbar seien, dass also folglich auch keines der drei anderen Elemente in dem der „story“ aufgelöst werden könne, ${ }^{171}$ dennoch scheint es, dass implizit die narrative Kategorie oft prioritär behandelt wird.

167 Wright, New Testament, 124.

168 Wright, New Testament, 125. Kursiv im Original.

169 Wright, New Testament, 124.

170 Wright, Faithfulness, 29 (Kombination von Elementen aus Wright, New Testament).

171 Wright, New Testament, 38: „... all worldviews contain an irreducible narrative element, which stands alongside the other worldview elements ... none of which can simply be ,reduced“ to terms of the others.“ 


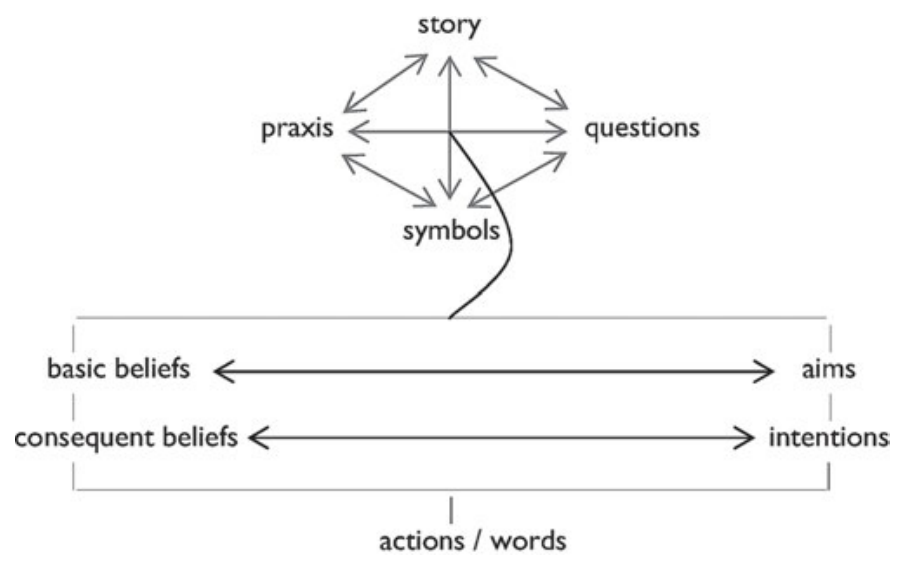

Abb. 58: Grundlagen der Weltbildanalyse nach N. T. Wright.

Denn wenn Wright über grundlegende Überzeugungen und Ziele einer Gesellschaft spricht, dann setzt er sie („sozusagen“/,as it were“) „shorthand forms of the stories which those who hold them are telling themselves and one another about the way the world is. " ${ }^{173}$ Während wertgeschätzte Symbole, tägliche Rituale und selbstlokalisierende Antworten auf grundlegende Fragen der Menschheit also darüber Aufschluss geben, wie wir denken und was wir entsprechend wollen, scheint es so, als ob für Wright diese Absichten wiederum durch zugrundeliegende Geschichten zusammengehalten würden. ${ }^{174}$

Entsprechend lässt sich auch eine Tendenz in der Wright'schen Analyse frühchristlicher Weltbilder ausmachen, Alltagsrealitäten (Praxis) der Kategorie der Geschichten unterzuordnen. ${ }^{175}$ Dies mag in Teilen natürlich mit der Datenlage zu tun haben (im Hinblick auf die Auferstehungs-Überzeugungen kann Wright etwa lediglich auf Bestattungsrituale etc. verweisen) ${ }^{176}$ oder auch mit der Darstellungsform (Wright schreibt eine kausale Geschichte über historische Ereignisse, kein

172 Wright, New Testament, 125.

173 Wright, New Testament, 125-126.

174 Vgl. Wright, New Testament, 123: „,... from those stories one can in principle discover how to answer the basic questions that determine human existence ... the stories that express the woldview, and the answers which it provides ... are expressed in cultural symbols.“

175 Heilig und Heilig, „Historical Methodology,“ 142-144. Wright, Faithfulness, 24-28 betont explizit, dass es ihm um eine „thick description“ geht und solche Engführungen weder in der Metapher noch in der Konzeption beabsichtigt sind. Dennoch ist zu fragen, ob seine Analyse in der Praxis nicht doch von dieser Zielsetzung abweichende Schwerpunktsetzungen vornimmt. 176 Vgl. die Diskussionen in Wright, Resurrection. 
Bilderbuch), ${ }^{177}$ ist wohl aber doch auch darin begründet, dass es letztendlich die narrativen Strukturen sind, welche als ordnende Größe in Wrights Entwurf der Weltanschauungs-Analyse auftreten.

Bedenkt man die epistemologische Relevanz der Kategorie der Erzählung (s. o.) ist dies auch nicht weiter verwunderlich: Insofern menschliches Denken fundamental narrativ strukturiert ist, ist die Dimension der Narrativität tatsächlich irreduzibel. Es wird daher verständlich, weshalb bei Wright Wertungen („What's wrong?“) durch Konstellationen innerhalb einer sich entfaltenden Geschichte erklärt werden, explizite Erzählungen aber andersherum nicht einfach auf statische Wertvorstellungen zurückgeführt werden.

In The New Testament and the People of God wendet Wright seine Weltanschauungs-Analyse auf das frühe Judentum an. Es werden die identitätsstiftenden Geschichten Israels analysiert, ${ }^{178}$ ebenso wichtige Symbole (Tempel, Land, Torah, ethnische Identität) ${ }^{179}$ und signifikante Praktiken (Gottesdienst und Feste, Studium, Anwendung der Torah). ${ }^{180}$ Auf dieser Basis werden dann die vier grundlegenden Fragen der Weltanschauungs-Analyse beantwortet: ${ }^{181}$

1. Who are we? We are Israel, the chosen people of the creator god.

2. Where are we? We are in the holy Land, focused on the Temple; but, paradoxically, we are still in exile.

3. What is wrong? We have the wrong rulers: pagans on the one hand, compromised Jews on the other, or, half-way between, Herod and his family. We are all involved in a lessthan-ideal situation.

4. What is the solution? Our god must act again to give us the true sort of rule, that is, his own kingship exercised through properly appointed officials (a true priesthood; possibly a true king); and in the mean time Israel must be faithful to his covenant charter.

Auf dieser Grundlage stellt Wright seinen Entwurf der jüdischen Überzeugungen vor, also derjenigen Grundannahmen, welche sich aus der Weltanschauung ergeben und dieser ihre Struktur verleihen. Die Kategorien, die er hier identifiziert und bespricht sind: Monotheismus, Erwählung und Eschatologie. ${ }^{182}$ Dem spezifischen Gepräge der letztgenannten Elements wird dann ein separates Kapitel gewidmet. ${ }^{183}$

177 Vgl. auch Wischmeyer, „Biblical Hermeneutics“ für die ganz zutreffende Wahrnehmung der hermeneutischen Rolle der Paraphrase und des Erzählens in der eigenen Darstellung bei Wright.

178 Wright, New Testament, 215-243.

179 Wright, New Testament, 221-232.

180 Wright, New Testament, 215-243.

181 Wright, New Testament, 243.

182 Wright, New Testament, 279. Vgl. S. 244-279.

183 Wright, New Testament, 280-338: „The Hope of Israel.“ 


\subsection{Das umfassende, implizite Narrativ des Paulus}

Im Rest von The New Testament and the People of God wird dann expliziert, wie die frühchristliche Weltanschauung - als Variation der frühjüdischen Weltanschauung - analysiert werden kann. Praxis, Symbole und grundsätzliche Fragen erhalten eine kurze, ${ }^{184}$ Geschichten eine längere ${ }^{185}$ Besprechung. Frühchristliche Theologie wird vor diesem Hintergrund in den genannten jüdischen Kategorien (wieder mit einem Schwerpunkt auf der Eschatologie) expliziert. ${ }^{186}$ Auf Paulus wird unter der Überschrift „Stories in Early Christianity“ eingegangen. ${ }^{187}$

Wie oben bereits erläutert (Kapitel 2, Abschnitt 2.4), knüpft Wright hier an Norman Petersens Unterscheidung von poetischer und referenzieller Sequenz an. Aus letzterer lässt sich eine Erzählwelt, die „narrative world of the text“ rekonstruieren. ${ }^{188}$ Diese möchte Wright nun bewusst nicht nur auf die konkrete Abfassungssituation des Schreibens bezogen wissen, er fragst stattdessen nach der „kind of story which formed [Paul's] larger narrative world.“189

Mit anderen Worten: Wenn Paulus im frühen Christentum und dessen fundamentalen Geschichten verortet wird, welche Geschichten treten dann hervor als irreduzibler Teil seines symbolischen Universums, als Größe, die seiner Weltanschauung Tiefe verleiht? ${ }^{190}$ Einerseits könnte, so Wright, natürlich die paulinische Biographie herangezogen werden, um eine solche referentielle Sequenz zu erstellen. Die Interpretation seines Alltags sei ja nicht zuletzt von seiner Vergangenheit als Pharisäer, seiner Berufung, der missionarischen und pastoralen Arbeit und der Hoffnung auf die zukünftige Auferstehung seiner eigenen Person geprägt gewesen. ${ }^{191}$ Explizit erzählt werde diese Geschichte, eine „deliberate and subversive variant of the Jewish story of the devout Pharisee," etwa in Phil 3,1-11. ${ }^{192}$ Die Relevanz einer solchen Analyse sieht Wright vor allem darin, dass sich auf dieser Ebene angebliche Berührungspunkte etwa zur Stoa als relativ oberflächlich erweisen würden, da diese Geschichte sich grundsätzlich von der narrativen Welt unterscheide, die wir etwa hinter Epiktets Dissertationes erkennen könnten. ${ }^{193}$

184 Wright, New Testament, 258-370.

185 Wright, New Testament, 371-443.

186 Wright, New Testament, 456-464.

187 Wright, New Testament, 403-409.

188 Wright, New Testament, 404.

189 Wright, New Testament, 404.

190 Wright, New Testament, 404.

191 Wright, New Testament, 404.

192 Wright, New Testament, 405.

193 Wright, New Testament, 405. 
Noch grundsätzlicher identifiziert Wright jedoch ein noch größeres implizites Narrativ als referentielle Sequenz hinter der - durch verschiedene rhetorische Bedingungen geprägten - poetischen Sequenz aller Briefe des Apostels:194

Paul presupposes this story even when he does not expound it directly, and it is arguable that we can only understand the more limited narrative worlds of the different letters if we locate them at their appropriate points within this overall story-world, and indeed within the symbolic universe that accompanies it.

Da diese grundlegende Geschichte nach Wright auch bei Paulus eine jüdische ist, kommen somit nun auch die alttestamentlichen Traditionen in den Blick, die „Geschichten Israels.“ Paulus folgt laut Wright den jüdischen Nacherzählungen seiner Zeit in vielem, weicht aber auch an entscheidenden Stellen von diesen ab: Auch er geht von der guten Schöpfung der Welt und von ihrem verkommenen gegenwärtigen Status aus. ${ }^{195}$ Abraham wird von ihm - ein Element, das Wright auch im zeitgenössischen Judentum lokalisiert ${ }^{196}$ - in dieser Fluchtlinie als Beitrag zur Lösung dieser Problematik aufgefasst. ${ }^{197}$ Abweichend von der Standard-Nacherzählung betont Paulus jedoch die Bedeutung des abrahamischen Segens für die gesamte Welt. ${ }^{198}$ Die Geschichte Israels als erwähltes Volk, dem der Wille Gottes offenbart ist, wird bei Paulus dann zu einer Unheilsgeschichte, denn Israel sei in der Wahrnehmung des Apostels eben nicht „Licht für die Welt“ und die Torah decke dies gerade auf. ${ }^{199}$ Dass Israel den Tod wähle, das „Exil,“ bedeute nun aber bei Paulus nicht mehr, dass dieses als noch immer andauernd zu verstehen sei. Vielmehr ist in Tod und Auferstehung Jesu die „Rückkehr aus dem Exil“ angebrochen. ${ }^{200}$ Die Zukunftserwartungen Israels - die Gabe des Geistes etwa - brechen daher in die paulinische Gegenwart hinein, eine neue Gemeinschaft entsteht. ${ }^{201}$ Die Theologie des Paulus kann nach Wright also nur innerhalb dieses „large-scale retelling of the essentially Jewish story, seen now

194 Wright, New Testament, 405.

195 Wright, New Testament, 405.

196 Vgl. kritisch Stuhlmacher, „Understanding.“

197 Siehe hierzu bereits den frühen programmatischen Beitrag von Wright, „Paul of History“ (jetzt Kapitel 1 in Wright, Pauline Perspectives), in welchem Wright eine Verbindung der Schwerpunkte von Stendahl und Käsemann versucht und dabei vor dem Hintergrund der Forschung Sanders' zum Judentum eine erste „neue Paulusperspektive“ formuliert.

198 Wright, New Testament, 405.

199 Wright, New Testament, 406.

200 Wright, New Testament, 406.

201 Wright, New Testament, 406. 
from the point of view of one who believes that the climatic moment has already arrived" verstanden werden. ${ }^{202}$

Entsprechend dieser grundsätzlichen Orientierung an der jüdischen, primär aus den heiligen Schriften gewonnenen Basis-Geschichte lässt sich die Theologie des Paulus daher auch als Modifikation der Kategorien Monotheismus, Erwählung und Eschatologie verstehen. ${ }^{203}$ Als im Grunde jüdische Geschichte fordert sie auch (weiterhin) pagane Konkurrenzerzählungen heraus. ${ }^{204}$ Integriert in die große Rahmen-Erzählung sieht Wright nicht nur Paulus' eigene (Lebens-) Geschichte, sondern auch - mit explizitem Verweis auf Hays - die Geschichte Jesu. ${ }^{205}$

In Paul and the Faithfulness of God werden all diese Andeutungen weiterentwickelt. ${ }^{206}$ Dies gilt einerseits für die beiden Richtungen, im Hinblick auf welche Paulus' spezifische Geschichte nach Wright zu verorten ist. So verteidigt Wright mit großem Aufwand seine Rekonstruktion einer „,continuous“ jüdischen Geschichte, ${ }^{207}$ insbesondere die fundamentale Rolle, die dabei der Gestalt des Abraham und der These der Empfindung eines anhaltenden Exils zukommen. ${ }^{208}$ Auch räumt er der Wiedergabe zeitgenössischer paganer Geschichten viel Platz ein und kommt am Ende von Paul and the Faithfulness of God auf die konkrete Herausforderung zu sprechen, welche sich für diese vor dem Hintergrund der paulinischen Geschichte ergab.

Vor allem aber widmet sich Wright in Kapitel 7 der genaueren Gestalt der paulinischen Geschichte. Er identifiziert drei ineinandergreifende Geschichten, von denen er sagt, dass sie ,a coherent interlocking shape, nesting within one another like the sub-plots in a play“ aufweisen würden. ${ }^{209}$ Die „äußere Erzählung“ sei die des Schöpfers und des Kosmos. Innerhalb dieser kosmischen Matrix sei ein Sub-Plot zu identifizieren, welcher sich mit der Menschheit - ihrem Sinn und Abirren und dem der ganzen Menschheit geltenden Segen an Abraham beschäftige. Auch wenn Paulus zuweilen auf diesen Sub-Plot fokussieren könne, darf dies nach Wright nicht darüber hinwegtäuschen, dass dieser an der Seite eines anderen Sub-Plots stehe, dem der Geschichte über Israel. Zentral sei

202 Wright, New Testament, 406.

203 Wright, New Testament, 407.

204 Wright, New Testament, 407.

205 Wright, New Testament, 407.

206 Er verweist auf den dritten (durch Wright, Resurrection zum vierten gewordenen) Band seiner Serie in Wright, New Testament, 405, Fußnote 108.

207 Wright, Faithfulness, 104.

208 Vgl. White, „Narrative Approach,“ 192-195.

209 Wright, Faithfulness, 474. 
zudem, dass diese drei Geschichten um den Messias Jesus herum modifiziert worden wären und sich auf diese Weise von ihren jeweiligen jüdischen Vorlagen abheben würden. ${ }^{210}$

Interessanterweise unternimmt Wright nicht den Versuch, weitere Sub-Plots zu identifizieren und zu beschreiben, auch wenn er einräumt, dass dies durchaus eine naheliegende Aufgabe wäre:211

\footnotetext{
There are, no doubt, several other „stories“ that one might detect in Paul. I have restrained myself in particular from setting out what seems to me a strong implicit story, consistent across his writings, about the people of God in the Messiah, indwelt by the spirit. As an excuse for this unwonted and no doubt unwelcome brevity, let me suggest that the „story of the church" is less a worldview element for Paul, and more of an actual argument, coming as it does on the surface of his letters rather than being embedded down below. He assumes the narratives of God and the world, of Israel and of Jesus: he expounds the narrative of the church. Worldviews are what you look through; but the church is what Paul regularly looks at.
}

Das Bild, das sich daher in Wrights Entwurf der impliziten Erzählung des Paulus in Paul and the Faithfulness of God ergibt, hebt sich erstaunlich von der methodologischen Grundlage ab, von welcher aus Wright seine Darstellung ursprünglich in The New Testament and the People of God unternommen hatte: Petersens Analyse der konkreten Erzählwelt eines bestimmten Briefes wird zunächst auf kosmische Maße ausgeweitet - um dann eben jene Erzählebene auszuklammern, für die Petersen dereinst nach der referentiellen Sequenz gefragt hatte.

\subsection{Narrative Strukturen unter der Textoberfläche}

In der bisherigen Diskussion des Wright'schen Ansatzes lag der Fokus auf der Rolle narrativer Strukturen im Erkenntnisprozess und darauf, wie diese in Wrights Sicht in der grundlegenden Relevanz von Erzählungen für die Konstitution von Weltanschauungen verankert ist. Darüber hinaus wurde die spezifisch paulinische Weltanschauung (das „mindset“) in der Rekonstruktion Wrights in Grundzügen vor Augen geführt, ein narrativ geprägtes Gebilde, das laut Wright trotz aller Modifikation durch das Christusereignis - eine jüdische Grundstruktur aufweist und sich daher aus der Schrift und daraus hervorgehenden und parallelen Traditionen speist.

210 Wright, Faithfulness, 531.

211 Wright, Faithfulness, 536. 
Damit ist jedoch noch nicht die gesamte Bandbreite dessen in den Blick genommen, worauf Wright mit der Betonung der Narrativität im Hinblick auf Paulus fokussiert. Zum einen stellt für Wright die Rekonstruktion des „worldview“ - bzw. des individuellen „mindset“ - lediglich eine Ausgangsposition zur Rekonstruktion der Theologie des Paulus dar, die dann anhand der Kategorien Monotheismus, Erwählung und Eschatologie erfolgt. ${ }^{212}$ Dunns Anfrage, ob hier nicht künstlich eigentlich bereits „theologische“ Aspekte in den Bereich der weltanschaulichen Voraussetzungen ausgelagert werden, ist sicherlich berechtigt. ${ }^{213}$ Teilweise mag diese Unklarheit und auch Redundanz damit zu tun haben, dass auch die gewählten „theologischen“ Kategorien letztlich ja nicht frei sind von der „weltanschaulichen“ Narrativität. ${ }^{214}$

Doch noch in einem weiteren Sinne kann gesagt werden, dass die Rekonstruktion der narrativen Struktur der jüdischen Geschichte(n) und der paulinischen Variation lediglich Voraussetzung ist für einen weiteren Schritt: Es geht Wright nämlich durchaus auch um den konkreten Beitrag für die Exegese paulinischer Briefe, der sich aus diesem Vorwissen ergibt. So schreibt er an zentraler Stelle, er werde demonstrieren, ${ }^{215}$

that looking at Paul's worldview with the aid of this narrative analysis sheds a positive flood of light - direct light, not surreptitious moonbeams - on passage after passage of tricky exegesis, and problem after problem in the theological coherence of the letters.

Als besonders umfassendes Beispiel eines solchen Textkomplexes, der nach Wright durch die Annahme eines formgebenden narrativen Prinzips „erhellt“ wird, sei auf eine frühere Arbeit verwiesen, in welcher Wright Röm 6-8 vor dem Hintergrund der Exodus-Erzählung auslegt. ${ }^{216}$

Die Annahme einer solchen Nacherzählung - in welcher Röm 6 den Durchzug durch das Meer widerspiegelt, Röm 7 die Gabe des Gesetzes und Röm 8 den Eintritt in das gelobte Land - erlaubt nach Wright nicht nur ein neues Verständnis

212 Siehe Wright, Faithfulness, Teil 2 und Teil 3.

213 Dunn, „Insider’s Perspective,“ 352: „The puzzle is that in these sections theology is inevitably present, and much would appear to be corollary to rather than preliminary to the exposition of Paul's theology.“

214 Siehe dazu unten, Abschnitt 4.4 zur hermeneutischen Dimension narrativer Elemente bei Hays und Wright.

215 Wright, Faithfulness, 474. Siehe auch die Aussagen die direkt folgen (S. 474-475) und betonen, dass die Rede von Kategorien wie die der Weltanschauung von ihm immer gemeint war als Hilfe, um wiederum zum Text zurückzukehren und diesen besser zu verstehen.

216 Siehe bereits Wright, Pauline Perspectives, Kapitel 11 („New Exodus, New Inheritance: The Narrative Substructure of Romans 3-8 [1999]“). Siehe Wright, Faithfulness, 659 für eine sehr kurze Zusammenfassung. 
zahlreicher Details dieser Passage, sondern auch eine Einbettung der Rede von der Gerechtigkeit Gottes in früheren Kapiteln des Römerbriefs in den Kontext der Geschichte Israels. ${ }^{217}$

Auch in Paul and the Faithfulness of God wird immer wieder der Anspruch erhoben, dass zentrale paulinische Texte erst dadurch verständlich würden, dass sie im Rahmen der oben beschriebenen umfassenden impliziten Erzählung interpretiert würden. Dass dieses Narrativ oft nur durch subtile Anspielungen an die Textoberfläche dringe, wird damit begründet, dass es für Paulus den normalerweise im Hintergrund bleibenden Verstehenshorizont bilde. ${ }^{218}$ Es wird in der im nächsten Abschnitt geschehenden Synthese zu fragen sein, inwiefern Wright hier direkt an Hays und dessen narrative Substrukturen anknüpft und wo er konzeptuell eigenständige Wege geht.

\section{Synthese}

\subsection{Vorbemerkung}

Nachdem die spezifischen Beiträge von Hays und Wright schlaglichtartig beleuchtet worden sind, soll in diesem Abschnitt eine kurze Zusammenschau der beiden Entwürfe geboten werden. Dabei soll herausgearbeitet werden, wo Konvergenzen und Überschneidungen festzustellen sind, wo allerdings auch je eigene Schwerpunkte gesetzt werden.

Das Ziel ist dabei insbesondere die Herausarbeitung derjenigen Aspekte, die sich direkt auf die Beschäftigung mit paulinischen Texten beziehen und in der englischsprachigen Auslegung in Anknüpfung an die beiden Exegeten mannigfaltig zur Anwendung gekommen sind. Die Leitfrage, auf deren Beantwortung die folgende Diskussion hinausläuft (unten, Abschnitt 4.5), ist also: Wie charakterisieren Hays und Wright diejenigen „impliziten“ narrativen Strukturen, die ihrer Ansicht nach im Vollzug der Exegese wahrgenommen werden müssen?

217 Vgl. aber auch schon seine Kommentare zur Kohärenz des Römerbriefs in der Rezension zu Käsemann, Römer (Wright, Pauline Perspectives, Kapitel 4 („New Tübingen School?“ [1982]), S. 62-64). In einem Antwortschreiben (S. 2; persönliche Kommunikation) identifiziert Käsemann genau hier die grundsätzliche Differenz und wirft Wright vor: „Immerhin müssen Sie nach meiner Meinung die paulinische Anthropologie ungemein reduzieren, um die ständige Beziehung auf Israel festhalten zu können.“

218 Einige Beispiele werden von White, „Narrative Approach,“ 195-199 besprochen. 


\subsection{Die grundsätzlich narrative Struktur von Weltbildern}

Wie oben gezeigt, geht Wright in einem besonderen Maße von der Zentralität narrativer Elemente für die Konstituierung von Weltanschauungen aus, was sich auch auf seine eigene Forschungsperspektive und damit auf die historische Methode der Exegese erstreckt. Hays ist in dieser Hinsicht zurückhaltender und möchte explizit keinen Anspruch zur narrativen Strukturierung der wahrgenommenen Wirklichkeit erheben.

Jedoch müssen diese expliziten Aussagen Hays' zumindest durch eine gegenläufige Beobachtung ergänzt werden: Auch wenn Hays sich dagegen wehrt, das Heranziehen der Kategorie der ,story' mit einer narrativen Struktur der menschlichen Wahrnehmung zu begründen, bedeutet dies nicht, dass er dieser nicht auch einen Wert jenseits der literarischen Analyse zuschreiben würde. Dies wird deutlich im Schlusskapitel, wo Hays - zugegebenermaßen dezidiert spekulativ - über die Möglichkeit spricht, Partizipation vor einem narrativen Hintergrund neu zu verstehen:219

If Paul's gospel is the story of Jesus Christ, then we might participate in Christ in somewhat the same way that we participate in (or identify with) the protagonist of any story. We find that the story lays a claim upon us and draws us into its world; we recognize ourselves in the protagonist and feel that our own destinies are somehow figured in his story.

Eine solche Teilhabe könnte „real“ sein, ohne „magisch“ gemeint zu sein. ${ }^{220}$ Diese Art von Partizipation - die nicht einfach mit Imitation verwechselt werden dürfe - hat laut Hays somit auch ethisches Potenzial. ${ }^{221}$ Mit Greimas gesprochen meint Hays daher: Der von Christus in der „topical sequence“ errungene Sieg sei kein Selbstzweck, sondern versetzte die Empfänger des Geistes nun in die Aktanten-Rolle des „Subjekts“ in der finalen Sequenz. ${ }^{222}$ Auch bei Hays scheinen Geschichten also durchaus auch eine epistemische Funktion zu erhalten - wobei eben trotzdem das spezifische Gepräge der Geschichte als Erzählung über die Treue des Messias wichtig bleibt.

\subsection{Narrative Elemente in der paulinischen Weltanschauung}

Die Weltanschauung des Paulus ist bei Wright - entsprechend seiner Ansichten zum Wesen von Weltanschauungen allgemein - durch narrative Strukturen

219 Hays, Faith, 214.

220 Hays, Faith, 215.

221 Hays, Faith, 223.

222 Hays, Faith, 223. 
geprägt. Erneut zeigt sich, dass Hays in dieser Hinsicht explizit Vorsicht signalisiert. Ihm geht es um das Faktum der narrativen Gestalt der paulinischen Verkündigung, in welcher er die Jesus-Geschichte das Zentrum darstellen sieht. Anders als Wright geht Hays also durchaus von einem expliziten Erzählakt aus, auch wenn dessen Produkt uns als Ganzes nicht mehr zugänglich ist.

Jedoch: Über die Annahme hinausgehend, dass diese Geschichte der Treue Jesu so zentral für das Wirken und Leben des Paulus gewesen sei, schimmert bei ihm auch durchgehend die Überzeugung durch, dass die paulinische Wahrnehmung der Welt als Ganzer nicht ohne diese „narrative Brille“ angemessen verstanden werden könnte. Gerade in der Auseinandersetzung mit der Frage nach dem Kern der paulinischen Theologie und in den Kommentaren zur „Gedankenwelt" des Paulus in der Neuauflage wird dies deutlich.

\subsection{Die theologische Relevanz narrativer Elemente}

Die narrative Gedankenwelt des Paulus findet ihren Ausdruck letztlich in ihrem Einfluss auf die Abfassung von Texten. Es ist diese Funktion, die in dieser Arbeit im Zentrum des Interesses steht. Es sollte jedoch zumindest kurz erwähnt werden, dass sich sowohl für Hays als auch für Wright die Bedeutung der Narrativität in dieser exegetischen Dimension noch nicht vollständig erschöpft. Vielmehr steht dieser Aspekt vermittelnd zwischen der Gedankenwelt des Apostels, welche in die Textproduktion eingeht, auf der einen Seite und der - auch theologischen Rezeption der Texte, deren Validität wiederum daran bemessen wird, wie treu sie an das narrative Gepräge der den Texten zugrundeliegenden Gedankenwelt anknüpft.

Dieser Aspekt kommt bei Hays vor allem in dessen theologiegeschichtlicher Einordnung des Apostels zum Ausdruck. Die Schwerpunktsetzung auf narrative Elemente bei Paulus lässt ihn nämlich eine Neuzuordnung des Apostels zu den anderen Autoren des Neuen Testaments und frühen Christentums erwägen, die aufs Ganze gesehen von mehr Kontinuität geprägt ist als Entwürfe, welche die „denkerische“ Qualität des Apostels in den Vordergrund stellen.

Der Paulus der genialen - oder schwer zu verstehenden - „Ideen“ ist zu einer einsamen Existenz im Kanon verdammt. ${ }^{223}$ Nimmt man jedoch wahr, dass auch in Paulus' Rechtfertigungslehre die in Kolosser- und Epheserbrief hervortretende kosmische Erlösungslehre vorausgesetzt sei, so verändere sich dieses Bild. ${ }^{224}$

223 Siehe Hays, Faith, 215-216.

224 Hays, Faith, 216. 
Das narrative Muster, welches Erlösung als kosmisches Ereignis betrachte, sei nicht weniger grundlegend für den Galaterbrief als für den Epheserbrief. ${ }^{225}$

Hays betont, dass die Polyvalenz des Narrativen durchaus unterschiedliche Deutungen zulasse und sein Argument daher nicht mit dem für theologische „Gleichheit“ verwechselt werden dürfe. ${ }^{226}$ Es sei aber durchaus festzuhalten, dass ein Fokus auf die den Briefen des Paulus zugrundeliegende narrative Struktur darauf hinweise, dass Paulus nicht so isoliert in der frühchristlichen Theologiegeschichte stehe, wie dies weithin angenommen werde. ${ }^{227}$ Selbst literaturgeschichtlich rückt Paulus mit seinem „Evangelium“ auf diese Weise an den Ausgangspunkt der Entwicklung von „Evangelien,“ d.h. „explicit literary articulations of the Jesus-story.“228

Kontinuität wird durch den Fokus auf narrative Elemente jedoch nicht nur gegenüber Zeitgenossen des Paulus hergestellt: Durch die Partizipation der Kirche an der Jesus-Geschichte ergibt sich in Hays' Sicht auch aus heutiger Sicht ein vielversprechender Anknüpfungspunkt für die theologische Auswertung der Paulusbriefe. ${ }^{229}$

Interessanterweise lässt sich bei Wright durch das Abheben auf eine zwar variierte aber doch in den Grundsätzen identische frühchristliche Grunderzählung als Teil einer geteilten Weltanschauung eine ganz ähnliche Dynamik erkennen. ${ }^{230}$ Der narrative Aspekt erlaubt folglich bei beiden Autoren einen hermeneutischen Zugang zur Theologie des Paulus, welcher diese auf neuartige Weise in den Dialog mit anderen frühchristlichen Entwürfen bringt.

Darüber hinaus behält diese narrative Dimension für Hays und Wright auch im weiteren, bis in die Gegenwart reichenden theologischen Diskurs ihre Bedeutung. Die Annahme von narrativen Strukturen hinter dem Text soll diesen nämlich nicht nur durchleuchten, mit dem Ziel das Gefundene dann in einen abstrakten Rahmen zu integrieren. Vielmehr fällt auf, dass sowohl bei Hays als auch bei Wright die Kategorie der Erzählung ihren hermeneutischen Eigenwert aufweist.

Im Hinblick auf Hays wurde bereits darauf verwiesen, wie dieser sich gegenüber einer nicht-narrativen (v. a. existentialistischen) Auflösung des Kerns paulinischer Theologie verhält. Ebenso wie diese Entwürfe oft nicht lediglich den Anspruch erheben, die Theologie der historischen Person des Paulus einzu-

225 Hays, Faith, 217.

226 Hays, Faith 217.

227 Hays, Faith, 218.

228 Hays, Faith, 219.

229 Zum Leitgedanken der Integration der Christen in eine Geschichte siehe dann später Hays, „Scripture.“ Siehe unten, Abschnitt 4.5.1.

230 Wright, New Testament, 371-417. 
fangen, sondern auch normative Interessen verfolgen - im Sinn einer aus den Briefen des Paulus zu gewinnenden angemessenen Rede von Gott - kann auch für Hays abgeleitet werden, dass das narrative Resultat der Exegese theologisch aufgearbeitet werden muss.

Diese Überzeugung spiegelt sich in Hays’ Beschreibung des Modus der paulinischen Kommunikation selbst wider. Gegen Ende seiner Arbeit bewegt sich Hays bewusst weg von der Diskussion um Methodik und hin zum Wesen der paulinischen Sprache. ${ }^{231}$ Er argumentiert, dass die Exegese mit ihrer Betonung des „Denkers“ Paulus den poetischen Charakter der Redeweise des Apostels zu wenig wahrgenommen habe. ${ }^{232}$ Damit meint Hays, dass ein angemessenes Verständnis der Paulusbriefe mit dem Subtilen und Indirekten rechnen müsse. Der Charakter der paulinischen Sprache gehöre „less to the sphere of wissenschaftliche Theologie than to the sphere of confession, prayer, and praise. " 233 Interpretation könne daher nicht in der Elimination aller Doppeldeutigkeiten bestehen, sondern vielmehr darin, aufmerksam die „,various overtones and ranges of implication“ der paulinischen Aussagen zu verfolgen.234 Gegenstand, Methodik und Ziel der Analyse greifen hier ineinander.

Bei Wright kann ein in gewissem Sinne paralleles dogmenkritisches Element identifiziert werden, wenn er - in seinen Augen - „anachronistischen“ systematisch-theologischen Kategorien frühjüdische Themenkomplexe gegenüberstellt. ${ }^{235}$ Es werden aber nicht einfach die einen Konzepte durch andere ersetzt. Vielmehr bleiben die von Wright eingeführten Größen in stetem Dialog mit ihrer narrativen Einbettung.

Eine Überführung in nicht-narrative dogmatische Kategorien ist zwar nach Wright durchaus möglich und unter bestimmten Umständen auch nötig (und diese müssen dann nicht zwangsläufig die frühjüdischen Kategorien sein). Es wird in seiner Sicht damit jedoch nicht das „Eigentliche“ der theologischen Analyse biblischer Texte erfasst. Wie sein Essay „Reading Paul, Thinking Scripture“ argumentiert, sind Dogmen vielmehr selbst „tragbare Erzählungen.“236 Sie komprimieren, erlauben die Verwendung in verschiedensten (etwa liturgischen) Kontexten, warten aber immer auch darauf, wieder entpackt zu werden. ${ }^{237}$

231 Hays, Faith, 226.

232 Hays, Faith, 227.

233 Hays, Faith, 228.

234 Hays, Faith, 229.

235 Vgl. hierzu Charlesworth, „Paradigm.“

236 Wright, Pauline Perspectives, 359.

237 Siehe zur hermeneutischen Relevanz die Besprechung von Wischmeyer, „Biblical Hermeneutics.“ 
Auch bei Wright spiegelt sich diese Wertschätzung für das Phänomen des Literarischen darin wider, dass er den poetischen Charakter der paulinischen Sprache betont - und sogar in seine eigene Darstellung mit aufnimmt. In diesem Sinn ist sein weit ausholender Entwurf mitsamt seinen lebhaften Assoziationen ein bewusster Gegenentwurf zur immer detaillierter werdenden Analyse immer kleinerer Textteile durch immer enger werdende Interpretations-Linsen innerhalb der Paulusforschung. ${ }^{238}$

\subsection{Narrative Strukturen an der Schnittstelle von paulinischem Denken und Schreiben}

\subsubsection{Das umfassendere implizite Narrativ (nach N. T. Wright)}

Bei Hays steht explizit die Jesus-Geschichte im Mittelpunkt. Bereits in The New Testament and the People of God nimmt Wright den von Hays auf narrative Substrukturen gelegten Fokus explizit auf, um sein grundsätzliches Vorgehen zu rechtfertigen. ${ }^{239}$ Wright integriert die Jesus-Geschichte jedoch unmittelbar in eine größere Erzählung - nicht jedoch in dem Sinn, dass erstere in letzterer aufgehen würde, sondern so, dass sie das entscheidende Element darstellt, an welchem sich Paulus von seinen jüdischen Zeitgenossen unterscheidet. ${ }^{240}$ Hays ist auch insofern für Wright relevant, als seine Arbeit Echoes of Scriptures in the Letters of Paul (siehe oben, Kapitel 2, Abschnitt 3.1) Wright einen methodischen Rahmen liefert, in welchem er von in subtilen Anspielungen auf alttestamentliche Geschichten „mitschwingenden“ narrativen Strukturen sprechen kann. ${ }^{241}$

In der Einleitung zur Neuauflage von The Faith of Jesus Christ nimmt Hays nun wiederum selbst explizit Stellung zu der Frage einer einen umfassenderen Rahmen liefernden Geschichte. Er betont, dass seine Arbeit zwar einen viel eingeschränkteren Fokus gehabt hätte, ihre Resultate aber selbstverständlich die folgende Frage aufwerfen würden: ${ }^{242}$

$[\mathrm{H}]$ how does the story of Jesus fit into the wider story of Israel, the story of election and promise told in the Old Testament?

238 Siehe hierzu vor allem Wischmeyer, „Biblical Hermeneutics.“

239 Siehe Wright, New Testament, 405 zu sowohl Hays, Faith als auch Hays, Echoes.

240 Wright, New Testament, 407: „,... these passages all show that the story of Jesus, interpreted precisely within the wider Jewish narrative world, was the hinge upon which Paul's rereading of that larger story turned.“

241 Siehe etwa Wright, Pauline Perspectives, 161: „Standing behind all of this is of course the major pioneering work of Richard Hays on Paul's echoing of scriptural passages and themes.“

242 Hays, „Introduction,“ xxxv. 
Hays skizziert einen Dialog mit Dunn, Wright und Martyn. Er hält fest, dass zum einen seine Analyse dem Gesetz eine Rolle zuweise, welche sich nicht so gut mit dem sanften Übergang vom Gesetz zu Christus bei Dunn in Übereinstimmung bringen lasse. ${ }^{243}$ Die Kreuzigung stelle ein radikales Element der Diskontinuität dar und sei daher mit Wrights Vorschlag des Exils als Bild für Israels Mangel vor dem Kommen Christi gut vereinbar. ${ }^{244}$ Während Hays bei Martyn das Element der Diskontinuität auf meisterhafte Weise herausgearbeitet sieht, meint er doch, er unterschätze den Grad, zu dem im Galaterbrief ,the story of Jesus' death and resurrection ... somehow the consummation of Israel's story“ sei. ${ }^{245}$

Dieser Aspekt der Apokalyptik verdient noch eine kurze Explikation. In The Faith of Jesus Christ spricht sich Hays noch dagegen aus, auf der Grundlage des Galaterbriefes den Status der Gemeinde auf „the apocalyptic consummation of the drama of salvation“ $z$ u beziehen. ${ }^{246} \mathrm{Er}$ begründet dies mit dem Fehlen apokalyptischer Themen im Galaterbrief. ${ }^{247}$ Diese Einschätzung nimmt Hays in der neuen Einleitung explizit zurück ${ }^{248}$ und verweist auf den Beitrag Martyns: „It now seems to me that Martyn has made a compelling case: Paul's theology in Galatians rests upon an apocalyptic narrative about the end of the old age and the beginning of a new one." ${ }^{249}$ Wrights Auseinandersetzung mit der apokalyptischen Paulus-Interpretation ist aufs Ganze gesehen kritischer. ${ }^{250}$ Er nimmt vor allem den Fokus auf der Diskontinuität zum Vorgehenden kritisch war. Paulus ist für inn ein durch und durch apokalyptischer Denker in einem Sinn, den Wright für frühjüdische Apokalyptik für angemessen hält: Während eschatologische Zukunftsbezüge nicht ausgeklammert werden, betont Wright vor allem die Rolle apokalyptischer Sprache als Werkzeug der Verdeutlichung der kosmischen Relevanz zeithistorischer Ereignisse. ${ }^{251}$ Als solche ist bei Wright die (recht verstandene) Apokalyptik eingebunden in jüdische narrative Strukturen über Schöpfung und Errettung. Demgegenüber scheint Hays, bei allen Einschränkungen, dem Ansatz von Martyn als Scheinwerfer auf einen Bestandteil der Israel-Geschichte mehr abgewinnen zu können. ${ }^{252}$

243 Hays, „Introduction,“ xxxvi-xxxvii.

244 Hays, „Introduction,“ $x x x v i i$.

245 Hays, „Introduction,“ xxxvii.

246 Hays, „Faith,“ 225.

247 Hays, „Faith,“ 224.

248 Hays, „Introduction,“ xxxviii.

249 Hays, „Introduction, “ xxxix.

250 Siehe nun die gegenüber Wright, Faithfulness etwas wertschätzendere Darstellung in Wright, Interpreters, Kapitel 6-9.155-186.

251 Siehe Wright, „Challenge“ in Auseinandersetzung mit Frey, „Demythologizing.“

252 Hays, „Introduction,“ xxxix. Siehe auch die in seinem Kommentar zum Galaterbrief vor-

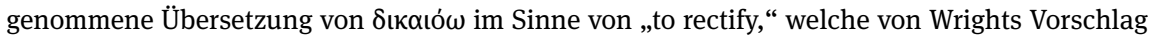
einer Feststellung der Bundesmitgliedschaft abweicht (Hays, „Galatians,“ 259). 
Interessanterweise hat Wright in seiner neuen Forschungsgeschichte zur paulinischen Exegese nun einen recht umfassenden Versuch unternommen, das fundamentale Anliegen der Neuen Paulusperspektive so darzustellen, als bestünde es in der Wahrnehmung dieser narrativen Kategorie. ${ }^{253}$ Für diese recht steile These lässt er Hays als Kronzeugen auftreten.

Zunächst merkt er im Hinblick auf Dunn kurz an, dass dieser wie er selbst zwar die Rekonstruktion Sanders' zum Judentum akzeptiert, allerdings dessen Verständnis des Paulus als höchst unbefriedigend empfunden habe. ${ }^{254}$ In einem längeren Abschnitt spricht er ihm dann das Verdienst zu, den von ihm, Wright, selbst in seinen früheren Vorschlag einer neuen Paulusperspektive ${ }^{255}$ noch nicht integrierten Aspekt der „Werke des Gesetzes“ verständlich gemacht zu haben. ${ }^{256}$

Der dritte mit Dunn verbundene Aspekt ist dann aber dessen Streit mit

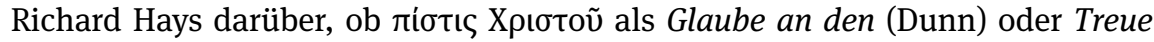
des (Hays) Messias zu verstehen sei. ${ }^{257}$ Wright schlägt sich auf Hays' Seite und insistiert, dass dies kein „small exegetical either/or“ darstelle. ${ }^{258}$ Vielmehr identifiziert er hier ein entscheidendes Element, das bei Dunn fehle - ein „narrative framework.“259 In der Tat ist es äußerst auffällig, dass Dunn in einem Abschnitt in „The New Perspective on Paul“ zwar zahlreiche Echos aus Wrights früherem Aufsatz zur universellen Bedeutung des Abrahambundes anklingen lässt, ${ }^{260}$ jedoch wenig begründet, weshalb für Paulus gelte: „the covenant should no longer be conceived in nationalistic or racial terms. "261 Abraham wird daher auch

253 Wright, Interpreters, 88-105.

254 Wright, Interpreters, 90-91.

255 Wright, „Paul of History“ (bzw. Perspectives, Kapitel 1).

256 Wright, Interpreters, 91-96.

257 Wright, Interpreters, 96-97.

258 Wright, Interpreters, 97.

259 Wright, Interpreters, 98.

260 Dunn, „New Perspective,“ 104: „In brief, Paul's new answer is that the advent of Christ had introduced the time of fulfillment, including the fulfillment of his purpose regarding the covenant. From the beginning, God's eschatological purpose in making the covenant had been the blessing of the nations: the gospel was already proclaimed when God promised Abraham, ,In you shall all the nations be blessed' (Gal. 3.8; Gen. 12.3; 18.18). So, now that the time of fulfillment had come, the covenant should no longer be conceived in nationalistic or racial terms. No longer is it an exclusively Jewish qua Jewish privilege. The covenant is not thereby abandoned. Rather it is broadened out as God had originally intended - with the grace of God which it expressed separated from its national restriction and freely bestowed without respect to race or work, as it had been bestowed in the beginning. This is roughly the argument of Gal. 3-4, as also developed later in Rom. 3-4.“

261 Dunn, „New Perspective,“ 104. 
weiter schlicht als „example“ bezeichnet, auf welches Paulus in einer eigentümlichen Hermeneutik Bezug nehme. ${ }^{262}$

Doch inwiefern liefert Hays dieses bei Dunn als fehlend monierte Bindeglied? Laut Wright impliziere das von Sanders entworfene Bild des Judentums von diesem selbst leider nicht-narrativ in der problematischen Kategorie des „Musters“ beschrieben ${ }^{263}$ - ein Narrativ der Erwählung und des Bundes, das in einer Frage gipfle. Nicht in der von Luther aufgeworfenen nach dem gnädigen Gott wohlgemerkt, sondern: „When will the gracious God fulfil his promises to Israel?"264 Was Hays schon in seiner Dissertation gesehen habe, sei die Tatsache, dass diese narrative Frage bei Paulus auch eine narrative Antwort erhalte: „the story of Jesus the Messiah." 265

Wright ist sich durchaus bewusst, dass Hays' Arbeit auch unabhängig von Sanders Rekonstruktion des Judentums verstanden werden kann. ${ }^{266}$ Insofern Sanders jedoch das Bewusstsein für die Situierung des Paulus im Judentum geschaffen habe und da Hays durch seine spätere Arbeit $\mathrm{zu}$ alttestamentlichen „Echos“ in den Paulusbriefen (die sich wiederum stark von Sanders absetzt, der von Schriftzitaten als bloßen „Beweistexten“ ausgeht) ${ }^{267}$ die Interaktion des Apostels mit der jüdischen Schrift betont habe, gehöre er sehr wohl in diese Forschungstradition. ${ }^{268}$

Die so gezogene Linie von Sanders über Hays zu Wright ist freilich nicht ganz ohne Brechungen: Mit Wrights auf Paulus bezogenen Worten könnte man vielmehr sagen, dass diese „Forschungsgeschichte“ in Wrights Rückblick um die große Kategorie der Narrativität herum „hermeneutisch rekonfiguriert“ - wenn nicht gar „gekreuzigt und zu neuem Leben erweckt“ - worden ist ... ${ }^{269}$

Nur so lässt sich wohl angemessen erklären, dass Wrights Schilderung des „Life after Sanders“ ihr Happy End in einer Charakterisierung des gegenwärtigen Forschers Hays als eine Art Wright redivivus (und anti-Dunn) findet:270

262 Dunn, „New Perspective,“ 110.

263 Vgl. die ausführliche Diskussion bei Wright, Interpreters, 73-75.

264 Wright, Interpreters, 97.

265 Wright, Interpreters, 98.

266 Wright, Interpreters, 99: „Hays’s proposal should ... properly be seen a spart of ,life after Sanders,' even though Sanders himself did not go that route and did not embrace it when offered. It may well be that Hays would have developed the same line of thought even if Sanders had never written a word.“

267 Vgl. Wright, Interpreters, 98-99.

268 Wright, Interpreters, 99.

269 Vgl. für dieses zugegebenermaßen polemische „Echo“ Wright, Interpreters, 101.

270 Wright, Interpreters, 99. 
I have detected a shift, over the last twenty years, between Early Hays and Later Hays on this point. In Echoes, the fundamental thrust is to see Paul thinking through Israel's scriptures in what might be called a typological manner. In the scriptures, Paul hears voices which echo and resonate with things that need to be said in and to his churches. There is no linear continuity ...

Während hier die Gemeinde „in parallel, rather than in continuity, with the ancient people of God" stehe, brächte Hays in neueren Arbeiten die Kategorien von „story“ und „echo“ zusammen: „The ,echoes“ are now to remind the ekklēsia of the earlier parts of their own story." ${ }^{271}$

Ganz unberechtigt ist Wrights Verweis auf eine solche Verschiebung des Schwerpunktes freilich nicht. In der Tat bringt Hays in einem eigenen Rückblick auf seine Forschung zum Ausdruck, dass er im Rahmen seiner Arbeit an einem Kommentar zum 1. Korintherbrief,, ${ }^{272}$ zur Erkenntnis gelangt sei, dass es Paulus' pastorale Strategie im Hinblick auf seine heidnischen Bekehrten gewesen sei, „to narrate them into Israel's story. “273 Ein vermehrter Fokus auf „narrative continuity with Israel's story" ist also in der Tat auszumachen. ${ }^{274}$

Besonders deutlich wird dies, wenn Hays im Hinblick auf die Rede von oi $\pi \alpha \tau \varepsilon \dot{\varepsilon} \varepsilon \varsigma \grave{\eta} \mu \tilde{\omega} v$ in 1 . Kor 10,1 anmerkt: ${ }^{275}$

For the predominantly Gentile Corinthian church, this is already an important gesture. Israel's story is not somebody else's history; rather, Paul addresses the Gentile Corinthians as though they have become part of Israel. They are invited to understand themselves now as descendants of the characters who appear in the pages of Scripture.

Auch ist von Wright richtig erkannt, dass Hays erstens dieses Element der Kontinuität mit dem Aspekt einer „radikal apocalyptic transformation“ in Beziehung setzt ${ }^{276}$ und dass Hays damit im Grunde sehr nahe an Wrights eigener Konzeption ist, da auch in dieser das Kreuz eine fundamentale Reinterpretation des jüdischen Narrativs nach sich zieht. ${ }^{277}$

Ganz lassen sich die beiden Ansätze allerdings wohl trotz aller kühnen Bemühungen Wrights nicht harmonisieren. Denn zumindest was die Schwer-

271 Wright, Interpreters, 100.

272 Hays, First Corinthians.

273 Hays, „Introduction,“ xi.

274 Hays, „Introduction,“ xi.

275 Hays, „Scripture,“ 9.

276 Hays, „Introduction, “ xi. Vgl. ausführlicher die Abgrenzung von einer „linear Heilsgeschichte in which Gentiles were simply absorbed into a Torah-observant Jewish Christianity“ bei Hays, „Scripture,“ 5.

277 Wright, Interpreters, 101. 
punktsetzung angeht, bleiben wichtige Unterschiede. Für Hays ist die Beobachtung, dass Paulus seine apostolische Berufung mit der ,apocalyptical interpretation of certain biblical texts that prefigure the events of the end time“ verbinde, der Ausgangspunkt der paulinischen Reflexion. ${ }^{278}$ Entsprechend lese Paulus die Schrift durch eine eschatologische Hermeneutik und verstehe die ,identity of the eschatological community through the lens of Scripture. “279 Da die Schrift also eschatologisch $\mathrm{zu}$ lesen ist und sich in der Gemeinde die eschatologische Gemeinschaft verwirklicht, lassen sich für Paulus Aussagen über Israel nun auf Heiden „,anwenden.“280

Die Tatsache, dass Paulus in 1. Kor 10,1-22 die Korinther in Kontinuität mit der Erzählung der „Väter“ in der Wüste verbindet, sei dementsprechend darin begründet, dass er die Gemeinde als an der Zeitenwende stehend versteht (1. Kor 10,11:

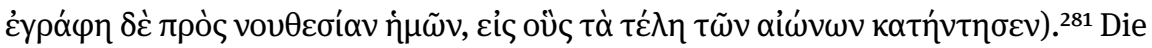

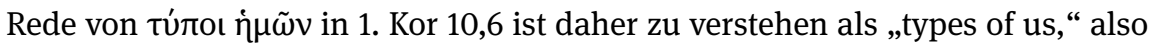
Präfigurationen der Gemeinde: „For Paul Scripture, rightly read, prefigures the formation of the eschatological community of the church." 282

Die von Hays postulierte paulinische Hermeneutik bleibt also auch hier ekklesiozentrisch. ${ }^{283}$ Da die Gemeinde das eschatologische, „rekonfigurierte“284 Gottesvolk darstelle, gelte: „all the scriptural narratives and promises must be understood to point forward to the crucial eschatological moment in which he and his churches now find themselves."285

Es ist daher dieser eschatologische Standort der Gemeinde ,within an apocalyptic narrative that locates present existence in the inverval between cross and parousia,“286 welcher ein „metaphorisches“ oder „typologisches“ Verständnis Israels auf die Gemeinde hin erlaube - und nicht so sehr ein prioritäres Bewusstsein, in einer einheitlichen Erzählung zu leben.

278 Hays, „Scripture,“ 4 mit Verweis auf Gal 1,15 und Jes 49. Zitat teilweise kursiv im Original.

279 Hays, „Scripture,“ 6.

280 Hays, „Scripture,“ 1 beginnt mit der Anspielung auf Jes 45,14 und Sach 8,23 in 1. Kor 14,25: Die im Kontext der alttestamentlichen Bezugsstellen geschilderte Hinwendung der Heiden zu Israel bildet den Hintergrund für das Verständnis der heidenchristlichen Gemeinde als Gottes Instrument der eschatologischen Bekehrung von „outsiders“ (vgl. Hays, „Scripture,“ 4).

281 Hays, „Scripture,“ 11.

282 Hays, „Scripture,“ 11.

283 Hays, „Scripture,“ 11 verweist explizit zurück auf seine frühere Formulierung einer „,ecclesiocentric hermeneutics“ in Hays, Echoes.

284 Hays, „Scripture,“ 5 in Anlehnung an Donaldson, Paul, 236.

285 Hays, „Scripture,“ 11 . Hervorhebung nicht im Original.

286 Hays, „Scripture,“ 21 mit Verweis auf 1. Kor 11,26. 
Entsprechend geht es Hays auch nicht so sehr darum, dass die Gemeinde nun das erwartete, wenn auch überraschende Ende der großen impliziten jüdischen Erzählung lieferte, als vielmehr - umgekehrt - darum, dass die Schrift etwas für die Orientierung der Gemeinde beisteuere, nämlich ein breiteres Narrativ, in welches hinein die Leser einen „metaphorical leap“ unternehmen und so „their own circumstances figured in the narrative“ vorfinden könnten. ${ }^{287}$ Zentral ist für Hays daher „the reader's act of imaginative identification with Israel,“288 „an imaginative projection of their lives into the framework of the Pentateuchal narrative.“"289

Am deutlichsten wird die hierin liegende Differenz wohl in der Lektüre der Figur des Abraham in Röm 4. Wright charakterisiert seine eigene Position wie folgt:290

Paul is expounding the covenant-making chapter (Genesis 15) in order to show that the revelation of God's righteousness in the gospel is (however shocking or paradoxical it may be) the fulfillment of this ancient promise.

Auch Hays lehnt die gängige Auslegung ab, wonach hier „a paradigm for the faith of Christian believers“ vorliege. ${ }^{291}$ Das Thema des Kapitels sei nicht die Weise, in welcher Abraham gerechtfertigt worden sei (aus Glauben), sondern „whose father he is and in what way his children are related to him." 292 Die auf diese Frage gegebene Antwort sei: der Vater sowohl der Juden als auch der Heiden, die alle an der Gerechtigkeit des Abraham, als einer ,inclusive representative figure,“ teilhaben. ${ }^{293}$

Einen „narrativen“ Erklärungsrahmen für Paulus’ Wahl dieser Geschichte liefert auch Hays, jedoch handelt es sich dabei wieder explizit um die Erzählung Jesu:294

Broadly speaking ... the relevance of Paul's appeal to the story of Abraham would lie in the fact that he finds there a precedent within Scripture for the idea that the faithfulness of a single divinely chosen protagonist can bring God's blessing upon „many“ whose destiny is figured forth in that protagonist's action. In this respect Abraham serves for Paul not just

287 Hays, „Scripture,“ 12.

288 Hays, „Scripture,“ 11. Hervorhebung nicht im Original. Vgl. Hays, „Scripture,“ 24.

289 Hays, „Scripture,“ 10.

290 Wright, Pauline Perspectives, 555-556.

291 Hays, „Abraham,“ 84. Der Aufsatz wurde bereits 1985 veröffentlicht, scheint jedoch nicht von Hays, „Scripture“ abgelöst zu werden.

292 Hays, „Abraham,“ 83.

293 Vgl. insbesondere Hays, „Abraham,“ 80.

294 Hays, „Abraham,“ 84. 
as an exemplar of Christian believing but also as a typological foreshadowing of Christ, the „one man“ (Rom 5,19) through whose obedience „the many were constituted righteous.“

Entscheidend ist hierbei aber nicht einfach, dass der Inhalt der als Bezugspunkt gewählten Erzählung ein anderer ist. Wichtig ist im Dialog mit Wright vor allem, dass die hier zum Ausdruck kommende paulinische Hermeneutik auch der viel späteren Ausformulierung in „Scripture and Eschatology in 1 Corinthians“ entspricht: Es ist die gegenwärtige Situation, das Bewusstsein, im Tod Jesu dem eschatologischen Handeln Gottes begegnet zu sein, die nach vergleichbaren Strukturen in der Schrift suchen lässt, um die am eigenen Leib erfahrene Konstellation zu beschreiben.

Auch wenn Paulus also sowohl nach Wright als auch nach Hays Geschichten erzählen kann, in welchen die Gemeinde an eine Stelle tritt, die aus jüdischer Perspektive dem ethnischen Israel vorbehalten geblieben wäre, so ist der Status dieser Erzählungen für das Denken des Paulus doch recht unterschiedlich zu bewerten. In Wrights Rekonstruktion steht der Exeget im Zentrum, für den sich das richtige Verständnis des paulinischen Evangeliums dann ergibt, wenn er voraussetzt, dass es die Lösung einer umfangreichen Erzählung darstellt. ${ }^{295}$ Bei Hays geht es hingegen darum, nachzuvollziehen, wie für Paulus selbst alttestamentliche Aussagen ihren Sinn erhalten, indem sie auf seine gegenwärtige Situation bezogen werden.296

Für die Suche nach einem „larger implicit narrative“ bedeutet dies, dass es im Verständnis Wrights notwendigerweise und vollumfassend vorauszusetzen ist - auch wenn es, als Element der Weltanschauung, nur partiell explizit zum Ausdruck kommt. Im von Hays angeregten Rahmen muss hingegen damit gerechnet werden, dass Paulus' Version von „Israel's story,“ wie sie hinter den paulinischen Texten steht, Lücken aufweist und auch in seiner Vorstellung nur insofern eine Ausformulierung erfährt, als sie für das ,eschatological Israel“ ${ }^{297}$ bedeutsam wird. Auch wenn sich das Erzählte der angenommenen umfassenderen Erzählung bei beiden Exegeten also zuweilen stark annähert, besteht doch ein großer Unterschied im Hinblick auf die angenommene Dynamik des zugrundeliegenden Erzählens.

In einem Punkt ist allerdings in der Tat eine Konvergenz der Vorstellungen des „späteren Hays“ mit Wrights größerem impliziten Narrativ festzustellen. In The Faith of Jesus Christ steht letztlich eine konkrete Erzählung im Hintergrund

295 Siehe bereits Wright, Perspectives („Paul of History“), 6.

296 Ich sehe hier im Unterschied zu Wright noch immer dieselbe Hermeneutik beschrieben, die Hays bereits mustergültig in Hays, Echoes, 94-102 skizziert hat,.

297 Vgl. Hays, „Scripture,“ 21. 
der Argumentation, die Verkündigung von der Treue Jesu. Im Aufsatz über das „Hineinerzählen“ der Korinther in die Erzählung Israels bleiben auch in der Tat Anklänge an diese frühere Arbeit bestehen, etwa wenn Hays schreibt: „Paul is arguing from the story, not narrating it as something new to his audience. “298 Jedoch darf diese Parallele nicht darüber hinwegtäuschen, dass im Hinblick auf umfassendere implizite Erzählungen auch ein Unterschied zu Hays' ursprünglicher Beschäftigung mit narrativen Substrukturen besteht: Der konkrete Beitrag des Paulus liegt nicht mehr so sehr in der aktiven Explikation der Signifikanz der (Jesus-)Geschichte, sondern in ,the way he brings the narrative of Israel into metaphorical conjunction with the issues the Corinthians face."299 Auch wenn die Exodus-Erzählung also als Text vorliegt, tut dies die narrative Verknüpfung von Israel und Gemeinde nicht notwendigerweise. Vielmehr handelt es sich bei dieser Verbindung um eine narrative Struktur, die Paulus der Imagination der Korinther nahelegt. ${ }^{300}$

Einerseits ist also an einem fundamentalen Unterschied zwischen dem Umgang der Exegeten mit dem auf den ersten Blick deckungsgleichen „larger implicit narrative“ festzuhalten: Bei Wright stellt es einen Verstehensrahmen dar, der als interpretative Kategorie nicht notwendigerweise explizit an Textoberflächen tritt. Bei Hays entsteht es immer wieder neu im Lichte des Christusereignisses und ist dabei auch von einem situativen Stimulus abhängig. Allerdings fällt eben auch auf: Gerade durch diesen Aspekt der narrativen Verknüpfung auf der Ebene der Imagination kommt letztlich auch Hays' Konzeption dieser Art von Erzählung der Wright'schen Variante nahe. Anders als in seiner Dissertation handelt es sich nun auch bei ihm um ein auch in letzter Instanz mentales Narrativ, welches auch ohne im Hintergrund stehende verbale Erzählung auskommt.

\subsubsection{Narrative Substrukturen (nach Richard B. Hays)}

Der letzte Abschnitt ist einem Aspekt der Kategorie der ,Erzählung، nachgegangen, die in der Regel mit der Person Wrights verbunden wird, die aber, wie gezeigt wurde, zumindest mit Modifikationen auch von Hays bemüht wird. Nun soll analog der Frage nachgegangen werden, inwiefern die von Hays in die Diskussion eingebrachte Konzeption der „narrativen Substruktur“ sich auch in der Exegese von Wright niederschlägt. Da bereits auf den Umstand verwiesen wurde, dass Wright eine solche Übernahme des Hays'schen Paradigmas für konkrete

298 Hays, „Scripture,“ 8.

299 Hays, „Scripture,“ 8.

300 Hays, „Scripture,“ 10 und vor allem 24. 
Textpassagen explizit vornimmt, kann hier der Fokus ganz auf die Frage gerichtet werden, wo Wright in seiner Anwendung von Hays' Vorarbeit abweicht.

Hierbei ist zunächst entscheidend, nach der Quelle der im Text fragmentarisch an die Textoberfläche tretenden Erzählung zu fragen. Bei Hays handelt es sich hierbei in The Faith of Jesus Christ um einen Inhalt (,story'), welcher der Leserschaft bereits aufgrund einer früheren Präsentation (dem „recital“ eines ,narrative') bekannt ist, nämlich aufgrund der Verkündigung des Paulus, der seinen Zuhörern Jesus als Gekreuzigten vor Augen gemalt hatte (vgl. Gal 3,1).

Auch wo (wie im letzten Absatz mit Bezug auf „Scripture and Eschatology in 1 Corinthians“ diskutiert) in der Arbeit von Hays das Postulat einer inhaltlich weiter gefassten zugrundeliegenden Erzählung erkannt werden kann, bildet ein konkreter Akt des Erzählens in der Vergangenheit immerhin - also auch wenn die „eigentliche“ narrative Verknüpfung erst in der Imagination der Teilnehmer/-innen der neuen Kommunikationssituation entsteht - einen Bezugspunkt, wenn es um das Erhellen bestimmter paulinischer Formulierungen geht: ${ }^{301}$

\footnotetext{
Even though Paul explicitly quotes just one biblical verse (Exod 32:6, in 1 Cor 10:7), his argument alludes to several episodes narrated in Exodus and Numbers and presupposes that his Corinthian readers are familiar with the story. Indeed, the people's central act of infidelity, the worship of the golden calf in Exod 32, is not explicitly described at all; instead, it is suggestively evoked by the oblique quotation of Exod 32:6, which connects idolatry with sitting down to „eat and drink“ - a connection that has considerable rhetorical force in Paul's argument against eating and drinking in pagan temples. This is a wonderful example of the figurative device of metalepsis: the full force of the quotation is apparent only to a reader who recognizes its original narrative context. Paul is arguing from the story, not narrating it as something new to his audience.
}

Bei Wright liegen die Dinge anders. Die für ihn zentrale Kategorie des „larger implicit narrative“ ist definitionsgemäß primär eine mentale Größe. Daraus folgt im Hinblick auf konkrete paulinische Texte zweierlei:

Es ist erstens nicht prinzipiell gesagt, dass dieses Narrativ, sofern es überhaupt an die Textoberfläche tritt, dies auf eine Weise tut, dass es den Diskurs strukturieren würde, also in Hays’ Sinn diesen Diskurs einer „narrativen Logik“ folgen lässt.

Doch selbst wenn man annimmt, dass dieses implizite Narrativ bestimmten Textpassage als Substruktur zugrunde liegt, bestünde doch noch ein wichtiger Unterschied zur Konzeption von Hays: Das, was dem Diskurs die Form verleihen würde, wäre auf der Ebene der Weltanschauung zu verorten, also prinzipiell zunächst erst einmal eine mentale Erzählung beziehungsweise eine Episode daraus.

301 Hays, „Scripture,“ 8. 
Entsprechend liest Wright Gal 3,1-4,11 nicht als Erläuterung der von Paulus in der Verkündigung explizit erzählten Jesus-Geschichte, sondern als argumentative Entfaltung des für das paulinische Weltbild zentralen narrativen Elements des Abrahambundes. ${ }^{302}$ Lediglich indirekt gibt es auch eine zu dieser „impliziten“ Erzählung korrespondierende explizite Erzählung, nämlich insofern wir es mit einer „expounding of the Abraham story“ zu tun haben und dabei die konkreten Texte in Gen 15, 12 und 18 das Material liefern. ${ }^{303}$ Wrights „narrative Substruktur“ geht jedoch nicht einfach in einer intertextuellen Beziehung auf, denn was an Gal 3-4 ,narratival“ ist, das ist eben gerade „the great covenant story from Abraham to the Messiah“"304 und damit eine aus der Schrift gespeiste, aber letztlich auf der Ebene der Weltanschauung rekonfigurierte und dort ihren eigentlichen Platz habende Erzählung.

Auch wenn Wright diese Differenzierung selbst nicht explizit vorzunehmen scheint, sind jedoch nicht alle von ihm identifizierten narrativen Echos in den Paulusbriefen unmittelbar Ausdruck dieser fundamentalen Erzählung, zumindest nicht auf dieselbe Weise. Das oben bereits angeführten Beispiel der erzählerischen Folge von Gang durch das Rote Meer, Gesetzgabe und Landnahme als eines strukturgebenden Interpretationsrahmens für Röm 6-8 veranschaulicht diese Beobachtung. In seinem Aufsatz geht Wright von der Beobachtung aus, dass in Röm 6,17-18 die Taufe mit der Befreiung aus der Sklaverei verbunden wird. ${ }^{305}$ Die Erzählung vom Exodus stellt in Wrights Sicht für Paulus das nächstliegende verbindende Moment dieser beiden Motive dar: ${ }^{306}$

There is no question that in Judaism in general any story about slaves and how they come to be free must be seen at once as an allusion to the events of the Exodus. When, in that context, we discover that the critical event in the story of the great liberation, the new exodus, is when the Christian passes through the water of baptism, we have (I suggest) a prima facie reason for making the same connection. „Sin,“ conceived here as an independent power takes of course the role of Egypt and/or Pharaoh; „righteousness, “ suggestively, seems to be almost a periphrasis for God.

Soweit ließe sich auch noch im Rahmen der klassischen Traditionsgeschichte argumentieren. ${ }^{307}$ Wrights narrativer Ansatz kommt nun im Austesten der

302 Siehe bereits Kapitel 7 („Curse and Covenant: Galatians 3.10-14“) und Kapitel 8 („The Seed and the Mediator: Galatians 3.15-20“) in Wright, Climax und nun Wright, Faithfulness, 860-879.

303 Wright, Faithfulness, 861.

304 Wright, Faithfulness, 862.

305 Wright, Pauline Perspectives, 166.

306 Wright, Pauline Perspectives, 166.

307 Wobei dies lediglich das Vorgehen, nicht aber das Ergebnis, betrifft. Siehe Vollenweider, Freiheit, 330: Die Verbindung von Taufe mit Bildern der Sklaverei und Befreiung erfolge zwar 
Reichweite des Einflusses dieser Erzählung - und damit ist nun die durch den alttestamentlichen Text tatsächlich erzählte Erzählung gemeint - zum Tragen: „If 6 tells the story of the Exodus, or at least the crossing of the Read Sea, the next thing we should expect is the arrival at Sinai and the giving of the Torah." ${ }^{308}$ Und dies sei natürlich „exactly the topic“ von Röm 7,1-8,11. ${ }^{309}$ Und auch 8,12-17 passe vorzüglich in diese „narrative sequence,“ insofern die Christen hier als „God's new Exodus-people“ beschrieben würden, die letztlich ihr Erbe erhalten, nicht ein Stück Land, sondern „nothing less than the renewed, restored creation.“310 Hier liegt also nach Wright der Fall vor, dass eine Erzählung einem paulinischen Text „,coherence“ verleihe ${ }^{311}$ - und damit eine Konzeption, die sehr nah an Hays' narrativer Logik zu stehen scheint.

Dass es sich hierbei um eine andere Art narrativer Substrukturen handelt, als Wright sie im Fall der impliziten großen Erzählung im Blick hat, zeigt eine zunächst unscheinbare Formulierung: Es handle sich um eine neue ExodusGemeinschaft. Auch in Paul and the Faithfulness of God wird immer wieder auf eine narrative Struktur verwiesen, die sich an der Exodus-Erzählung orientiert und an zahlreichen Stellen der Paulusbriefe anklingt. Auch dort ist dann die Rede von einem „neuen“ oder „wahren“ Exodus-Volk, ${ }^{312}$ von der Eucharistie als „culmination, climax and paradoxical meaning of the ancient Jewish story for which Passover and Exodus were the prototype,“313 von der Exodus-Erzählung „now coming to new expression in the Messiah and the Spirit, "314 davon, dass man über 2. Kor 6,14-7,1 sagen könne, ,the whole passage is framed as a new exodus“315 und davon, dass in 1. Kor 10 das Volk des Messias seine „own Exodus-journey“ habe. ${ }^{316}$

erst bei Paulus, sie lasse jedoch keinen einheitlichen Motivhintergrund erkennen. Vollenweider sieht die Rede vom Herrschaftswechsel primär im „durch das Judentum geprägten positiven Verständnis der Knechtschaft unter Gott“ verwurzelt an, warnt jedoch vor einer monokausalen „Herleitung“: „Wie in 1/2 Kor wirken im vorliegenden Zusammenhang eher die naheliegenden hellenistischen Metaphern von Freiheit und Sklaverei als jüdische Exodus- und Passatraditionen ein.“ Auch was diese angeht, warnt Vollenweider (S. 325-326) vor einer zu simplizistischen „Ableitung“ der Verhältnisbestimmung von Freiheit und Knechtschaft aus sozialen Gegebenheiten. Vgl. auch die kritische Anmerkung von Wischmeyer, „Biblical Hermeneutics,“ 82.

308 Wright, Pauline Perspectives, 162-163.

309 Wright, Pauline Perspectives, 163.

310 Wright, Pauline Perspectives, 163.

311 Wright, Pauline Perspectives, 163.

312 Wright, Faithfulness, 422.

313 Wright, Faithfulness, 428. Komplettes Zitat kursiv im Original.

314 Wright, Faithfulness, 543.

315 Wright, Faithfulness, 714.

316 Wright, Faithfulness, 1070. 
Vergleichbares ließe sich nun aber in Bezug auf Abraham eben gerade nicht sagen. Die Galater sind nach Wright gerade nicht wie Abrahams Erben, sie sind es vielmehr selbst. ${ }^{317}$ Es besteht natürlich in Wrights Vorstellung durchaus eine gewisse Beziehung zwischen Paulus' Umgang mit der Abrahams-Erzählung auf der einen Seite und mit der Exodus-Erzählung auf der anderen. Denn auch die Parallelisierung mit der Gemeinde im letztgenannten Fall basiert in seiner Sicht darauf, dass die Ereignisse des Exodus Teil derselben Geschichte sind, die sich von der Verheißung an Abraham bis zur Erfüllung in der Gemeinde erstreckt. ${ }^{318}$ Insofern die mit dem Exodus verbundenen Ereignisse Teil einer Erzählung sind, aus welcher sich das Judentum als Ganzes herleitet, ${ }^{319}$ stehen sowohl Abraham als auch die Wüstengeneration in der „Vorgeschichte“ der Gemeinde. Dennoch: Nur die Abrahamsgeschichte „erzählt“ prophetisch von Zukünftigem und handelt damit von der Gegenwart des Paulus. Demgegenüber liegen die Ereignisse, auf welche sich die Exodus-Erzählung bezieht, gänzlich in der Vergangenheit.

Wenn Wright daher davon spricht, dass das Argument von Röm 8 zusammengehalten werde von der „Exodus story, now rethought in and through Jesus and the Spirit,"320 dann ist damit gemeint, dass Paulus eine neue Geschichte erzählt, die sich in ihrer „narrativen Sequenz" an der Exodus-Erzählung anlehnt. Entsprechend handelt es sich bei der in Röm 7,1-8,11 zum Ausdruck kommenden Handlung auch nicht um eine ,slavish typology in which he merely reproduces the earlier story point by point in its new guise." ${ }^{321}$ Dies geht schon daher nicht, weil die den befreiten Sklaven des ursprünglichen Exodus gegebene Torah paradoxerweise „part of the enslavement from which the second Exodus frees the people of God“ wurde. ${ }^{322}$

Wenn Wright daher im Fortgang seines Aufsatzes Röm 6-8 mit Röm 1-5 zu verweben versucht, indem er von Röm 4 ausgehend die Erfüllung der Verheißung an Abraham in das Zentrum stellt, ${ }^{323}$ so geht dies nicht ohne Spannungen. Der Unterschied ist, dass Paulus Wrights Meinung nach Gen 15 als einen Text liest, der direkt auf die Zeit des Apostels verweist, während die Exodus-Erzählung in Anlehnung an 1. Kor 10 als vom historischen Israel handelnd, jedoch Strukturparallelen zur Gemeinde aufweisend verstanden wird. Entsprechend spielt

317 Wright, Interpreters, 101.

318 Wright, Interpreters, 100. Vgl. Wright, Pauline Perspectives, 164 zur Verzahnung der Exodus-Ereignisse mit der Abrahams-Erzählung.

319 Wright, Faithfulness, 118-125.

320 Wright, Pauline Perspectives, 163. Hervorhebung nicht im Original.

321 Wright, Pauline Perspectives, 163.

322 Wright, Pauline Perspectives, 163.

323 Wright, Pauline Perspectives, 164. 
die Exodus-Erzählung in Wrights umfangreicher, sich über mehr als 100 Seiten erstreckender Rekonstruktion des „larger implicit narrative“ des Paulus auch so gut wie keine Rolle. ${ }^{324}$

Man muss im Hinblick auf Wright also zumindest unterscheiden zwischen narrativen Substrukturen, welche (a) auf den gegenwärtigen Zeitabschnitt des „larger implicit narrative“ fokussieren, und solchen, die (b) gegenwärtige Ereignisse mit Hilfe von Mustern aus auf die Vergangenheit abzielenden Erzählungen zum Ausdruck bringen. Die Exodus-Substrukturen scheinen zumindest auf den ersten Blick der letztgenannten Kategorie anzugehören.

Wright selbst hat jedoch gerade im Hinblick auf die Exodus-Erzählung noch auf eine dritte Möglichkeit einer narrativen Substruktur hingewiesen. Er argumentiert, dass das Judentum zur Zeit des Paulus seine Situation als ,anhaltendes Exil“ wahrgenommen hätte. Die in Dtn 27-30 zum Ausdruck kommende Sequenz von verheißenem Exil und Rückführung habe sich nach dieser Ansicht als noch nicht völlig abgeschlossen dargestellt. ${ }^{325}$ Wenn Esra in Neh 9 die gegenwärtige Situation beschreibt, so klingt darin die Erfüllung zahlreicher Vorhersagen der Propheten noch nicht an - im Hintergrund steht dementsprechend vielmehr die Erinnerung an die Gefangenschaft in Ägypten: ${ }^{326}$

This cannot be the time of Isaiah 40-55 had in mind, or the great renewal spoken of in the last twenty or so chapters of Ezekiel. „We are still slaves“; and slaves need an Exodus, a fresh act of liberation, a new Moses, a victory over the pagan tyrants who still oppress them.

Diese „Rückkehr aus dem Exil“ - und damit dieser „zweite Exodus“ - läge also von dieser Perspektive der Propheten aus betrachtet noch in der Zukunft. ${ }^{327}$ Wright spricht daher auch schon im Hinblick auf Ezekiel und Jesaja 40-66 von einer „Exodus-hope.“328 Zumindest durch diese prophetische Vermittlung liefert die Exodus-Erzählung (c) daher durchaus eine narrative Struktur, die sich - ganz wie die Erfüllung der Abrahams-Verheißung - auf die Zukunft bezieht: ${ }^{329}$

Any second-temple Jew, reading the Exodus narrative and knowing the present Temple to be frustratingly incomplete, would pick up the sense of closure in the text, the fresh act of grace through which YHWH came, despite everything, to dwell with his people, and would

324 Wright, Faithfulness, 456-569. Die größten Ausnahmen stellen Wright, Faithfulness, 498 und Wright, Faithfulness, 501 dar.

325 Wright, Faithfulness, 139-163.

326 Wright, Faithfulness, 151.

327 Vgl. Wright, Faithfulness, 178: „We are waiting for a new Exodus, and perhaps a new Moses to lead it."

328 Wright, Faithfulness, 655.

329 Siehe etwa Wright, Faithfulness, 679. Hervorhebung nicht im Original. 
long for the same thing to happen once more, for the prophecies of Isaiah 40.5 to come true (,Then the glory of YHWH shall be revealed, and all people shall see it together'), for the prayer of Isaiah 64.1 to be answered (,0 that you would tear open the heavens and come down, so that the mountains would quake at your presence'). The Exodus-narrative, in other words, would point forwards to the moment when Israel's eschatological monotheism would be fulfilled, and YHWH would return to his people at last.

Vor diesem Hintergrund müsse nach Wright die Rede von der „Herrlichkeit Gottes im Gesicht des Messias Jesus“ (2. Kor 4,6) verstanden werden als die Versicherung, dass der Gott, der Israel im Exil verlassen, aber versprochen hätte, zurückzukehren - ,as he had done in Exodus after the threat of withdrawing his ,presence““ - letztlich im Messias Jesus zurückgekehrt sei. ${ }^{330}$

Ganz ähnlich spricht Wright kurz darauf zusammenfassend davon, dass man an mehreren paulinischen Schlüsselstellen „the overtones of that Exodus-based narrative which formed the basis for the hope that YHWH, having long since abandoned Jerusalem to its fate, would one day return to save his people and to establish his glorious presence in the temple" erkennen könne. ${ }^{331}$ Eine solche „Exodus-Substruktur“ - die somit als dritte zu den beiden oben genannten Kategorien hinzutritt - erhellt die Argumentation, etwa von Passagen wie 2. Kor 4,3-6, dadurch, dass die Exodus-Erzählung sekundär auf Ereignisse in der Gegenwart verweist.

Für die Exegese ist die hier vorgenommene Differenzierung bedeutsam, weil nur im ersten und dritten Fall (welcher bei Wright zudem oft nicht explizit vom zweiten Fall abgegrenzt wird) die - in der Paulusforschung recht umstrittene Gesamtrekonstruktion eines umfangreichen weltanschaulichen Narrativs des Paulus notwendig ist. Nur hier wird die narrative Substruktur dadurch konstituiert, dass Ereignisse miteinander verbunden werden, deren zeitgenössische sinnhafte Verknüpfung strittig ist - ob also beispielsweise für das Judentum im Allgemeinen oder Paulus im Speziellen tatsächlich angenommen werden kann, dass Abraham in der Erzählung als Lösung für das von Adam verursachte Problem auftritt. $^{332}$

Der zweite Typ narrativer Substrukturen unterscheidet sich hiervon markant, da er nicht von der der These eines "common Jewish narrative“333 und dessen

330 Wright, Faithfulness, 679.

331 Wright, Faithfulness, 689. Vgl. Wright, Faithfulness, 721: „What the one God of Israel had done in the Exodus narrative, and had promised to do himself at the eschaton, Paul sees being accomplished by the spirit.“

332 Siehe etwa Stuhlmacher, „Understanding.“

333 White, „Narrative Approach,“ 191-195. 
Bedeutung für Paulus ${ }^{334}$ abhängig ist. Die Frage, ob Paulus das Motiv der Freiheit in Röm 6 in Anlehnung an die jüdische Tradition vom Exodus formuliert, setzt schließlich lediglich voraus, dass Paulus mit den Erzählungen um diese Geschehnisse vertraut ist. ${ }^{335}$ Eine Kritik des Wright'schen Umgangs mit Erzählungen bei Paulus kann daher nicht pauschal an der Fragwürdigkeit des weltanschaulichen Narrativs anknüpfen. Zumindest im Einzelfall kann auch Wright auf konkrete Erzähltexte als Vorlage verweisen, sodass seine exegetischen Vorschläge entsprechend geprüft werden müssen. ${ }^{336}$

\section{Das Verhältnis von „narrative substructures“ und „,larger implicit narrative“}

\subsection{Protoerzählungen als gemeinsamer Bezugspunkt}

Im Rahmen des „,narrative approach“ ist mit der Rede von der „Erzählung“ in der Regel gerade nicht gemeint, dass ein Text vorliegt, welcher die oben (Kapitel 3, Abschnitt 3.4) diskutierten Kriterien einer expliziten Erzählung erfüllen würde. In Teil III dieser Arbeit wurde daher die grundsätzliche Frage erörtert, wie aus narratologischer Sicht mit nicht explizit erzählten Erzählungen umgegangen werden kann. Dabei haben sich die Kategorien der mentalen Narrativisierung und der daraus hervorgehenden Protoerzählung als naheliegende Konzeptionen angeboten (Kapitel 9) und in der Anwendung auf die Paulusbriefe auch als heuristisch wertvolle Werkzeuge erwiesen (Teil IV).

Von diesem neugewonnen Bezugspunkt ausgehend - und nachdem die Schwerpunktsetzungen von Hays und Wright ausführlich wahrgenommen wurden - kann nun die Frage geklärt werden, in welchem Verhältnis die Entwürfe von Hays und Wright zu dieser Kategorie des „mentalen Erzählens“ stehen. Aus dem jeweiligen Verhältnis zur Kategorie des Protonarrativs (und seiner im Zuge der Narrativisierung entstehenden Vorstufen) kann dann abgeleitet werden, wie die beiden Zugänge narratologisch zu bewerten sind und wie die jeweils in den Blick genommenen Phänomene des Textes in der Praxis der Exegese aufgegriffen werden können.

334 Vgl. White, „Narrative Approach,“195-199.

335 D. h., wir bewegen uns hierbei auf ganz anderem Grund, als wenn wir erwägen, ob die Rede von der „Rechtfertigung“ so zu verstehen ist, dass damit auf den mit Abraham geschlossenen, bis in die Gegenwart reichenden Bund Bezug genommen wird.

336 Zur angemessenen Methodik dieser Beurteilung siehe unten, Kapitel 17. 
Wie herausgearbeitet wurde (siehe Abschnitt 4.5.2), teilt sich die von Hays als „narrative Substrukturen“ bezeichnete Größe mit der Wright’schen Konzeption eines weltanschaulichen Narrativs die Tatsache, dass beide mit Texten in Verbindung gebracht werden können, die selbst keine expliziten Erzählungen darstellen.

Beide Kategorien scheinen sich jedoch auch tendenziell voneinander abgrenzen zu lassen, insofern sie sich im Hinblick darauf unterscheiden, in welchem spezifischen Verhältnis das mentale Narrativ zum untersuchten Text steht:

(1) Bei Wright tritt die Erzählung zumindest punktuell deutlich zu Tage, insofern einzelne Momente explizit angesprochen werden. Die narrative Verknüpfung bleibt (zumindest stellenweise) implizit, da sie lediglich auf mentaler Ebene durchgängig vorliegt.

(2) Im Fall von Hays' Entwurf liegt in gewisser Hinsicht die umgedrehte Konstellation vor: Hier haben wir es in der Vorstellung von Hays mit einem recht durchgehenden Einfluss auf die Textoberfläche zu tun - der jedoch nicht notwendigerweise an einer konkreten Stelle durch einen expliziten Bezug auf eine Erzählung in Erscheinung treten muss.

Die diskutierten (siehe Abschnitt 4.5) Überschneidungen in der Anwendung der beiden Konzeptionen ergibt sich aus dem Umstand, dass Hays' Verständnis von Narrativität zumindest ansatzweise ähnlich vom geäußerten Text wegstrebt, wie dies für Wrights Definition gilt. Hays identifiziert narrative Substrukturen in nicht-narrativen Texten, die er als „unfolding of the meaning of [a] story“ versteht. ${ }^{337}$ Wie bereits in Kapitel 2, Abschnitt 2.3 festgestellt wurde, schweigt er sich zur narrativen Verwirklichung dieser „story“ (dem „narrative“ als „recital“ der „story“) aus. Obwohl Hays also die paulinische Verkündigung als wichtigen Bezugspunkt voraussetzt, lenkt er auf diese Weise den Blick weg vom Aspekt der Textualität, also weg vom Konzept der ,Erzählung‘ im Sinn von Köppe und Kindt.

Somit scheint es auf den ersten Blick auch nicht naheliegend, die Kategorie der narrativen Substruktur als ein grundsätzlich intertextuelles Phänomen zu verstehen. In der narratologischen Diskussion des Wesens impliziter Erzählungen wurde jedoch deutlich, dass die Rede einer „story,“ der Verweis auf etwas Erzähltes, eine Erzählung voraussetzt - und damit einen Erzählakt, entweder verbal (schriftlich oder mündlich) oder zumindest mental simuliert (Kapitel 9, Abschnitt 4). Es ist folglich durchaus möglich, die Kategorie der narrativen Substruktur zu explizieren, indem man diese auf andere Erzählungen bezieht: Eine 
narrative Substruktur im Sinne Hays' liegt demnach dann vor, wenn eine Erzählung die Ausgestaltung eines nicht-narrativen ${ }^{338}$ Textes beeinflusst.

Es wird unten (Kapitel 16) noch zu explizieren sein, was mit diesem Einfluss genau gemeint sein kann und in welchen Phänomenen im beeinflussten Text er resultiert. Für den Moment interessiert aber vor allem der Aspekt der beeinflussenden Erzählung: Worum handelt es bei dieser? Eine Möglichkeit ist, dass der Autor in der Abfassung seines Textes von einem schriftlich oder mündlich versprachlichten Narrativ beeinflusst wurde - etwa von einer Passage aus dem Alten Testament oder einem Ausschnitt einer Predigt. Auch hier verläuft der Einfluss des Textes aber natürlich nicht unmittelbar, sondern über das erinnerte Erzählte. ${ }^{339}$ Mit diesem eingeräumten Zwischenschritt einer mentalen Vermittlung ist jedoch auch bereits der Weg für eine weitere Möglichkeit geebnet, nämlich dafür, dass es sich bei der in Frage stehenden Erzählung selbst um ein mentales Protonarrativ handelt, welches nirgendwo explizit erzählt wird.

Was bedeutet dies nun für das Verhältnis der von Hays und Wright jeweils betonten narrativen Aspekte? Eine Integration der beiden Schwerpunktsetzungen scheint möglich, wenn man das „larger implicit narrative“ von Wright als ein bestimmtes Protonarrativ und damit als eine mögliche Quelle narrativer Substrukturen versteht.

Eine solche Einordnung des von Wright bemühten weltanschaulichen Narrativs als einer fragmentarisch an die Textoberfläche tretenden Protoerzählung scheint aufgrund des folgenden Zitates äußerst angebracht: ${ }^{340}$

The story functions precisely at the level of worldview, normally out of sight but occasionally summoned into view to undergird the more obvious surface concerns.

Die Charakterisierung des „larger implicit narrative“ als einer primär mentalen Erzählung schließt natürlich nicht aus, dass dieses Narrativ in einem weiteren Schritt auch explizit erzählt werden könnte. Immerhin stehen wir gerade in den paraphrasierenden Abschnitten in Wrights Arbeiten selbst einer sprachlichen Umsetzung (seiner Rekonstruktion) der paulinischen Protoerzählung gegenüber! Eine Einordnung als primär mentale Erzählung ist davon unbenommen gerechtfertigt, weil das von Wright ins Auge gefasste Narrativ seiner Ansicht nach bei Paulus nirgends als Ganzes in narrativer Form textlich auftritt. Möchte man also

338 Dasselbe gilt grundsätzlich auch für die Strukturierung von narrativen Vertextungen, auch wenn Hays dieses Phänomen nicht in das Zentrum seines Interesses stellt. Siehe unten, Abschnitt 5.3.

339 Vgl. dazu oben, Kapitel 9, Abschnitt 3.3.

340 Wright, Faithfulness, 128. Hervorhebung nicht im Original. Vgl. oben, Kapitel 9, Abschnitt 4. 
das „larger implicit narrative“ in seiner Gesamtheit charakterisieren, liegt eine Einordnung als Protonarrativ auf der Hand.

Beim von Wright ins Auge gefassten Protonarrativ handelt es sich natürlich um ein sehr spezifisches: Der Punkt, in welchem Wright über Petersen hinausgeht, ist ja gerade die These, dass von der einem einzelnen Brief „innewohnenden“ Geschichte über dessen Abfassungssituation ausgehend auch ein einheitliches „larger implicit narrative“ erhoben werden kann, das allen Briefen des Paulus zugrunde liegt. ${ }^{341}$

Terminologisch könnte man erwägen, dieses spezifische Gepräge des Ansatzes von Wright dadurch zum Ausdruck zu bringen, dass man von einem Metanarrativ (im Singular!) spräche. ${ }^{342}$ Damit hätte man ein sprachlich passendes Gegenüber zur „Substruktur“ von Hays zur Verfügung, das nicht nur kommunizieren würde, dass diese Erzählung „hinter“ dem produzierten Text steht, sondern auch, dass sie einer höheren Ordnung angehört, also auch die narrative Situiertheit des Autors selbst mit einschließt. ${ }^{343}$ Allerdings wird das Adjektiv „metanarrativ(e)“ in der Erzähltheorie bereits als Bezeichnung für sprachliche Äußerungen verwendet, die eine Erzählung als Thema haben. ${ }^{344}$ (In dieser Arbeit wird dementsprechend mit dieser Bezeichnung auch auf den spezifischen Kommentar des Erzählers zum eigenen Erzählen verwiesen, z. B. im Hinblick auf Gal 1,20.) ${ }^{345}$

Häufig wird das Nomen auch synonym mit dem „grand narrative“(oder: „master narrative“) verwendet. ${ }^{346}$ Nun ist es so, dass Wrights Kategorie dieser Konzeption durchaus in mancherlei Hinsicht ähnelt - so gilt auch für letztere, ,[that it] may exist as collective beliefs rather than as the message of particular texts.“" ${ }^{347}$ Andererseits involviert Wrights Rekonstruktion der jüdischen Erzählung aber Individuen und konkrete Objekte und ist daher nicht nur metonymisch „narrativ.“348

Wir begnügen uns daher in terminologischer Hinsicht mit der Charakterisierung des von Wright ins Auge gefassten Phänomens als „Protoerzählung“ und setzen in der Rede über die allgemein-jüdische und spezifisch-paulinische Protoerzählung voraus, dass in diesem Fall im Sinne Wrights entsprechend umfassende und einheitliche simulierte Erzählungen gemeint sind.

341 Wright, New Testament, 404-405.

342 So beispielsweise - allerdings ohne große theoretische Rechtfertigung - bei Eskola, Narrative Theology.

343 Vgl. etwa White, „Narrative Approach,“ 185.

344 Prince, Dictionary, 51. Vgl. Nünning, „Metanarrative Comment,“ 305 zur Differenzierung zwischen „metanarrative“ and „metafictional.“

345 Siehe oben, Kapitel 8, Abschnitt 3.5.2.

346 Vgl. Nünning, „Functions, “ 15.

347 Ryan, „Narrative,“ 344.

348 Vgl. Ryan, „Narrative,“ 348. 
Akzeptiert man die Einordnung der von Wright fokussierten Größe als ein spezifisches umfassendes Protonarrativ, so stellt es in der Tat eine von mehreren möglichen Quellen für eine narrative Substruktur im Sinne Hays' dar.

Diese Inbeziehungsetzung vom „larger implicit narrative“ und der narrativen Substruktur über die Kategorie des Protonarrativs stellt auch eine zufriedenstellende Erklärung für die Beobachtung dar (vgl. Abschnitt 4.5), dass es in der Praxis zu Unklarheiten in der Zuordnung kommen kann: Manche Phänomene scheinen lediglich einer der beiden Kategorien anzugehören, andere fallen in beide zugleich, da diese überlappen. Bei den beiden Kategorien handelt es sich schließlich nicht um klassifikatorisch gleichwertige und einander ausschließende Konzeptionen. Vielmehr kann Wrights „larger implicit narrative“ zuweilen auch als Substruktur auftreten (zumindest in der Exegese der beiden Neutestamentler, ob dies auch für die Paulusbriefe gilt, ist natürlich erst noch zu klären).

Für die Textanalyse ergibt sich hieraus folgende doppelte Konsequenz:

(1) Wer an einer Identifizierung von narrativen Substrukturen interessiert ist, der hat neben expliziten Erzählungen, die als Vorlage in Frage kommen, auch mit der Möglichkeit zu rechnen, dass der Diskurs von einem lediglich impliziten Protonarrativ - vielleicht sogar von Wrights spezifischem ,larger implicit narrative“ - geprägt ist.

Selbst wo ein mündlich oder schriftlich vorliegender narrativer Text einen anderen Diskurs beeinflusst, wird dies in der Regel die mental vergegenwärtigende Repräsentation von Ereignissen auf Seiten des Autors voraussetzen, also seine spezifische Interpretation und vielleicht auch mentale Nacherzählung der Vorlage. Damit ist im Umkehrschluss auch klar: Wird in einem Text eine narrative Substruktur identifiziert, so wird dadurch in der Regel auch eine „mental story“ (Ryan) beziehungsweise eine Protoerzählung postuliert und nicht nur die sklavische Reproduktion einer textlichen Vorlage gemeint.

(2) Für die Rekonstruktion von Protoerzählungen - auch die des spezifischen von Wright postulierten „larger implicit narrative“ - gilt wiederum, dass narrative Substrukturen Aufschluss über die Handlung dieser mentalen Erzählung geben könnten. Denn wer Protoerzählungen evidenzbasiert rekonstruieren möchte, ist auf das fragmentarische Auftreten dieser impliziten Erzählung im Text angewiesen.

Und als Erzählfragmente kommen in Frage: (1) kleinere explizite Erzählungen als Episoden des größeren impliziten Protonarrativs, (2) Bezüge auf einzelne Ereignisse des Narrativs - und auch (3) narrative Substrukturen. Denn eine narrative Substruktur wird nach Hays zu einer solchen, indem sie die Form des Textes auf die ein oder andere Weise beeinflusst - und so zum fragmentarischen Ausdruck einer Protoerzählung und für den Exegeten zugänglich wird. 
Im folgenden Abschnitt soll die hier vorgenommene Inbeziehungsetzung dadurch illustriert werden, dass die Optionen systematisch entfaltet werden, die sich in der Beschäftigung mit konkreten Texten ergeben, wenn man den von Hays und Wright jeweils betonten Aspekten nachgeht.

\subsection{Optionen im Umgang mit konkreten Texten}

\subsubsection{Explizite Erzählungen als Produkt eines singulären Erzählaktes}

Liegt ein Text vor, der als explizite Erzählung klassifiziert werden kann, so lässt sich diese narrative Vertextung selbst aus narratologischer Perspektive beschreiben. In vielen Fällen (sowohl fiktionaler als auch faktualer) Erzählungen wird die Handlung erst im Akt des Erzählens ausgestaltet, das Arrangement und die Verknüpfung der (entweder beobachteten oder lediglich imaginierten) Ereignisse erfolgt also in unmittelbarer zeitlicher Nähe zum Erzählakt, bzw. parallel zu diesem. In diesem Fall ist es sinnvoll, lediglich von „einem“ - mündlichen oder schriftlichen - Erzählakt zu sprechen.

\subsubsection{Explizite Erzählungen als Produkt eines geprobten Erzählaktes}

Während Hays besonders das „organische Verhältnis“ von impliziten Erzählungen zu nicht-narrativen Vertextungen (d.h. von „story“ und „argument“) einer Rechtfertigung bedürfend ansieht, ${ }^{349}$ darf jedoch nicht aus dem Blickfeld geraten, dass es durchaus auch eine (I) Verbindung von mentaler Protoerzählung und mündlich/schriftlich geäußerter Erzählung geben kann. Denn Hays selbst gibt ja zu verstehen, dass narrative Substrukturen „discourse“ ganz allgemein untermauern könnten. Mit folgenden beiden Fällen ist daher zu rechnen:

Der Erzählakt selbst kann (1) im Fall einer längeren Reflexionsperiode, anders als einleitend skizziert, natürlich auch schon mental „geprobt“ worden sein, sodass man hier durchaus vom Vorhandensein einer Protoerzählung sprechen könnte, welche der expliziten Erzählung vorausgeht. ${ }^{350}$ Diese Konstellation dürfte für Alltagserzählungen sogar den Standardfall darstellen (beispielsweise, wenn der Ehemann auf dem Nachhauseweg vom Pub darüber grübelt, wie er seiner Frau die Gründe seiner Verspätung darlegen wird). Lediglich im Fall einer unerwarteten Konfrontation oder Aufforderung zum Erzählen kann mit einer erzählerischen Improvisation gerechnet werden.

349 Vgl. Hays, Faith, 22.

$350 \mathrm{Zu}$ den verschiedenen Phasen der Textproduktion siehe oben, Kapitel 9, Abschnitt 4. 
Letztlich handelt es sich bei der hier angesprochenen Kategorie um mehrere Erzählakte (um mindestens einen mentalen und einen lautlich/schriftlich wahrnehmbaren), bei denen allerdings die Handlung der beiden Erzählungen mehr oder weniger identisch sein dürfte - es sei denn, das Feedback des Gegenübers (z. B. durch die Mimik oder Einwürfe) erfordert noch während des Äußerungsaktes eine spontane Anpassung nicht nur der Art und Weise der Narration, sondern auch des erzählten Inhalts. ${ }^{351}$

Diese Art der narrativen Substruktur ist naturgemäß kaum identifizierbar. Aus narratologischer Perspektive scheint die Wahrnehmung, dass Erzählungen auf einen unterschiedlich ausführlichen Reflexionsprozess zurückzuführen sind und sich dies auch auf der Grundlage der Stringenz der Narration teilweise bewerten lässt, ausreichend. ${ }^{352}$

\subsubsection{Explizite Erzählungen mit Einfluss anderer Protoerzählungen}

Ebenso denkbar ist jedoch der Fall (2), dass ein Protonarrativ die Ausgestaltung einer expliziten Erzählung beeinflusst, die in einem weitaus weniger engen Verhältnis zur mentalen Erzählung steht.

So kann die explizite Erzählung etwa das Thema ${ }^{353}$ übernehmen (z. B. „Treue“), jedoch eine andere Handlung aufweisen, da sie auf andere Erzählfiguren fokussiert (z. B., so die These von Hays, „Treue Jesu“ auf der einen und „Treue der Christen" auf der anderen Seite).

Ebenso kann die explizite Erzählung aber auch ein ganz anderes Thema als die Protoerzählung aufweisen und dieser lediglich in anderen Aspekten etwa der chronologischen Ordnung und sinnhaften Verknüpfung der Ereignisse (vgl. bei Hays „sequence“ und „shape“) - folgen.

Ein Narrativ kann auch dadurch die Narration einer anderen Erzählung beeinflussen, dass die Darstellung einer Erzählfigur diesem Vorbild folgt. ${ }^{354}$ (So

351 Wird in einem ersten Durchgang die geplante Geschichte als unzureichend empfunden, kann sie natürlich noch abgeändert werden. Im Normalfall dürfte dann jedoch eine erneute Simulation erfolgen, welche dem letztlich geäußerten Produkt bereits recht nahe käme.

352 Ein Parameter wäre etwa, ob im Text platzierte Vorausdeutungen später auch eingelöst werden oder nicht. Die Möglichkeit einer tatsächlichen Prolepse (ohne spätere Thematisierung derselben Situation) muss dabei aber natürlich auch berücksichtigt werden. Siehe grundsätzlich oben, Kapitel 11, Abschnitt 3.2.

353 Vgl. hierzu oben, Kapitel 3, Abschnitt 5.3.

354 Vgl. Köppe und Kindt, Erzähltheorie, 135 zur „Typisierung“ von Figuren. Siehe auch S. 146158 zu Figuren als Bedeutungsträger und die Diskussion auf S. 155-157 zur Beziehung zwischen Erzählfiguren und der Wirklichkeit bzw. anderen Erzählungen. 
hat etwa Works kürzlich postuliert, dass in 1. Kor 5, 6-8 und 10,1-22 die Gemeinde die Rolle der Wüsten-Generation in der Exodus-Erzählung übernimmt.) ${ }^{355}$

\subsubsection{Explizite Erzählungen als Fragment umfassenderer Protoerzählungen}

Es ist noch eine zweite Abweichung (3) von der in (1) genannten Konstellation möglich. Selbst wenn die explizite Erzählung wie in (1) der simulierten Protoerzählung selbst folgt, muss sie in der sich anschließenden tatsächlich geschehenden Äußerung nicht notwendigerweise vollständig zum Ausdruck kommen.

Es ist also durchaus mit dem Fall zu rechnen, dass Ereignisrepräsentationen im Text so verbunden sind, dass sie die Bedingungen für eine Einordnung als explizite ,Erzählung، rechtfertigen, dass es sich bei der entsprechenden Handlung jedoch nur um eine einzelne Episode eines umfassenderen Erzählzusammenhangs handelt. Eine explizite Erzählung kann folglich unter Umständen auch nur als Fragment eines größeren Protonarrativs verstanden werden.

\subsubsection{Nicht-Erzählungen mit Einfluss von Protoerzählungen}

Ein Einfluss von Protoerzählungen kann - mehr im Interesse von Hays selbst natürlich auch (II) die Ausgestaltung nicht-narrativer Texte beeinflussen. Es handelt sich dabei also beispielsweise um deskriptive oder argumentative Vertextungen. Im Normalfall dürfte es sich hierbei um Texte handeln, in welchen sprachliche Ereignis-Repräsentationen vorliegen. Erfolgte bereits im Mentalen des Autors eine narrative Verknüpfung dieser Ereignisse und kann dies aus dem Text erschlossen (oder aus anderen Gründen, etwa weil der Autor uns darüber in Kenntnis gesetzt hat, vorausgesetzt) werden, ${ }^{356}$ hätte man anhand eines nichtnarrativen Textes eine Protoerzählung rekonstruiert.

In den meisten Fällen wird eine solche Rekonstruktion nur deswegen möglich sein, weil temporale und sinnhafte Verknüpfungen zumindest ansatzweise aus dem Text selbst erschlossen werden können. Das Protonarrativ hat dann die Strukturierung des Diskurses - d.h. etwa den Aufbau des Arguments - beeinflusst, liegt also als Substruktur im untersuchten Text vor. ${ }^{357}$

355 Works, Church. Vgl. hierzu kritisch die Schlussfolgerungen von Vollenweider, Freiheit, 398 zum „Desinteresse am Exodusereignis,“ welches er mit der „Abwertung des Sinaigeschehens“ verbunden sieht.

356 Vgl. oben, Kapitel 9, Abschnitt 4 zu den paratextlichen Hinweisen im Klappentext zu den von Queneau gebotenen „Stilübungen.“

357 Der Fall, dass eine Protoerzählung fragmentarisch so chaotisch an die Textoberfläche tritt, dass sie nicht im eigentlichen Sinn als „strukturierend“ gelten kann, ist theoretisch durchaus denkbar. Allerdings hätten wir dann auch kaum eine Gelegenheit, sie überhaupt zu identifizie- 


\subsection{Zielsetzungen im Umgang mit konkreten Texten}

Die Ausgestaltung der Kategorie der impliziten Narrative bei Hays und bei Wright geht mit einem unterschiedlichen Interessenschwerpunkt einher: Hays' erklärtes Hauptanliegen ist es, die Form und Struktur konkreter Texte besser zu verstehen. Bei Wright geht es umgekehrt primär darum, aus konkreten Texten ein einheitliches, das Weltbild bestimmende Narrativ zu synthetisieren.

Entsprechend sind die genannten Optionen für das Verhältnis von Protoerzählungen und tatsächlich geäußerten Texten in unterschiedlicher Weise für die zu differenzierenden Anliegen von Hays auf der einen und Wright auf der anderen Seite relevant:

- Die Frage eines mentalen Probelaufs eines denselben Inhalt betreffenden Erzählaktes (Abschnitt 5.2.2) ist beispielsweise aus narratologischer Sicht durchaus für die Beschreibung des Erzählens expliziter Erzählungen - und damit weder für Hays noch von Wright - von Interesse: Lässt sich an der Art und Weise, wie das Erzählte entfaltet wird, erkennen, dass der Erzähler die Narration im Vorhinein vorbereitet hat oder/und das Erzählte ein zwischen Erzähler und Leserschaft geteiltes Wissen darstellt? ${ }^{358}$

- Lediglich für Wrights grundsätzliches Anliegen von Interesse ist (Abschnitt 5.2.4) der Fall, dass eine explizite Erzählung im Text ein Fragment des von ihm angenommenen Protonarrativs darstellt. ${ }^{359}$

- Für das Anliegen von Hays wiederum sind Fälle relevant, in denen entweder eine explizite Erzählung (Abschnitt 5.2.3) durch andere (Proto-)Narrative geprägt ist oder (Abschnitt 5.2.5) ein nicht-narrativer Text der Struktur einer Erzählung folgt. Hier ist tatsächlich von einer „narrativer Substruktur“ zu sprechen. Auch Wright hat unter Umständen ein Interesse an diesem Phänomen, nämlich genau dann, wenn die als Substruktur den Diskurs beeinflussende Protoerzählung den von Wright postulierten Inhalt hat, also als Ganzes

ren, es sei denn, es handelt sich hierbei etwa um ein literarisches Experiment und der Autor informiert uns im Kontext darüber, dass im Text einzelne Ereignisse einer gedachten Erzählung eingebaut sind, auch wenn deren Reihenfolge und Verknüpfung nicht den Verhältnissen in der erzählten Welt entsprechen. Selbst bei der extravaganten Umsetzung der Alltagserzählung in Queneaus Stilübungen als „Interjektionen“ bleibt aber die temporale Ordnung als strukturierendes Prinzip der zugrundeliegenden Protoerzählung erkennbar (Queneau, Stilübungen, 115): „Psst! Äh! Ah! Oh! Hm! Ah! Uff! Ey! Na! Oh! Phh! Boah! Zu! Hu! Au! Ey! He! Äh! Pfft! [Anm.: Umbruch] Na! Ey! Phh! Oh! Äh! So!“

358 Vgl. dazu oben, Kapitel 8, Abschnitt 3.

359 Die von Hays besprochenen Texte Gal 3,13-14 und 4,3-6 sind ja gerade nicht so narrativ verbunden, dass sie aufeinander folgende Episoden desselben impliziten Narrativs darstellen würden. Vgl. oben, Kapitel 3, Abschnitt 4.3. 
oder teilweise der Handlung des „larger implicit narrative“ entspricht. Unter diesen Umständen fallen die Interessen der beiden Exegeten weitestgehend zusammen.

Nicht alle Fälle, in welchen narrative Substrukturen vorliegen, sind somit für Wright relevant. So ist es möglich, dass (Abschnitt 5.2.3) eine explizite Erzählung durch eine Protoerzählung geprägt ist oder (Abschnitt 5.2.5) eine Protoerzählung einem nicht-narrativen Text als narrative Substruktur Form verleiht, sie aber jeweils nicht in das „larger implicit narrative“ integriert ist. Für die Exegese im Allgemeinen sind selbstverständlich auch diese Fälle von Bedeutung, da im Anspruch Hays' gilt, dass der betreffende Diskurs ohne Voraussetzung der narrativen Substruktur unverständlich bleiben würde. ${ }^{360}$

Wenn daher im folgenden Kapitel 16 der Frage nachgegangen wird, was bei der Suche nach konkreten Substrukturen zu beachten ist, wird dabei keine Unterscheidung zwischen solchen Strukturen gemacht, die für Wrights spezifisches Anliegen bedeutsam sind und solchen, die „nur“ einer Erhellung des Textsinns dienen. 